\title{
A novel reflectance-based model for evaluating chlorophyll concentrations of fresh and water-stressed leaves
}

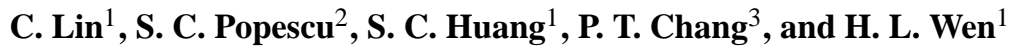 \\ ${ }^{1}$ Department of Forestry and Natural Resources, National Chiayi University, Chiayi, Taiwan \\ ${ }^{2}$ Department of Ecosystem Science and Management, Texas A\&M University, College Station, Texas, USA \\ ${ }^{3}$ Department of Horticultural Science, National Chiayi University, Chiayi, Taiwan \\ Correspondence to: C. Lin (chinsu@mail.ncyu.edu.tw)
}

Received: 21 August 2013 - Published in Biogeosciences Discuss.: 18 November 2013

Revised: 5 March 2014 - Accepted: 10 November 2014 - Published: 6 January 2015

\begin{abstract}
Water deficits can cause chlorophyll degradation which decreases the total concentration of chlorophyll $a$ and $b$ (Chls). Few studies have investigated the effectiveness of spectral indices under water-stressed conditions. Chlorophyll meters have been extensively used for a wide variety of leaf chlorophyll and nitrogen estimations. Since a chlorophyll meter works by sensing leaves absorptance and transmittance, the reading of chlorophyll concentration will be affected by changes in transmittance as if there were a water deficit in the leaves. The overall objective of this paper was to develop a novel and reliable reflectance-based model for estimating Chls of fresh and water-stressed leaves using the reflectance at the absorption bands of chlorophyll $a$ and $b$ and the red edge spectrum.

Three independent experiments were designed to collect data from three leaf sample sets for the construction and validation of Chls estimation models. First, a reflectance experiment was conducted to collect foliar Chls and reflectance of leaves with varying water stress using the ASD FieldSpec spectroradiometer. Second, a chlorophyll meter (SPAD-502) experiment was carried out to collect foliar Chls and meter readings. These two data sets were separately used for developing reflectance-based or absorptance-based Chls estimation models using linear and nonlinear regression analysis. Suitable models were suggested mainly based on the coefficient of determination $\left(R^{2}\right)$. Finally, an experiment was conducted to collect the third data set for the validation of Chls models using the root mean squared error (RMSE) and the mean absolute error (MAE). In all of the experiments, the observations (real values) of the foliar Chls were extracted
\end{abstract}

from acetone solution and determined by using a Hitachi U2000 spectrophotometer.

The spectral indices in the form of reflectance ratio/difference/slope derived from the $\mathrm{Chl} b$ absorption bands ( $\rho_{645}$ and $\left.\rho_{455}\right)$ provided Chls estimates with RMSE around $0.40-0.55 \mathrm{mg} \mathrm{g}^{-1}$ for both fresh and water-stressed samples. We improved Chls prediction accuracy by incorporating the reflectance at red edge position $\left(\rho_{\mathrm{REP}}\right)$ in regression models. An effective chlorophyll indicator with the form of $\left(\rho_{645}-\right.$ $\left.\rho_{455}\right) / \rho_{\text {REP }}$ proved to be the most accurate and stable predictor for foliar Chls concentration. This model was derived with an $R^{2}$ of $0.90(P<0.01)$ from the training samples and evaluated with RMSE 0.35 and $0.38 \mathrm{mg} \mathrm{g}^{-1}$ for the validation samples of fresh and water-stressed leaves, respectively. The average prediction error was within $14 \%$ of the mean absolute error.

\section{Introduction}

Photosynthesis is the largest-scale synthetic process on earth. There are many kinds of photosynthetic pigments, i.e., chlorophylls, carotenoids, and phycobilins in plant leaves, but chlorophylls are considered to be the key factor because the photochemical reactions take place only at the trapped chlorophyll molecules. Light absorbed by chlorophyll excites electrons in the molecules, enabling them to be transferred to other molecules for glucose production and thus enabling vegetation growth. Chlorophyll content can directly determine photosynthetic potential and primary production (e.g., Whittaker and Marks, 1975). It is believed that about 
Table 1. Previously developed spectral indices for foliar chlorophyll estimation.

\begin{tabular}{|c|c|c|}
\hline Index & Formula & Source \\
\hline Vogelmann red edge index 1 & $\operatorname{Vog} 1=\rho_{740} / \rho_{720}$ & Vogelmann et al. (1993) \\
\hline Vogelmann red edge index 2 & $\operatorname{Vog} 2=\left(\rho_{734}-\rho_{747}\right) /\left(\rho_{715}+\rho_{726}\right)$ & Vogelmann et al. (1993) \\
\hline Vogelmann red edge index 3 & $\operatorname{Vog} 3=\left(\rho_{734}-\rho_{747}\right) /\left(\rho_{715}+\rho_{720}\right)$ & Vogelmann et al. (1993) \\
\hline Red edge NDVI & $\mathrm{NDVI}_{705}=\left(\rho_{750}-\rho_{705}\right) /\left(\rho_{750}+\rho_{705}\right)$ & $\begin{array}{l}\text { Gitelson and Merzlyak } \\
(1994 a, b)\end{array}$ \\
\hline $\begin{array}{l}\text { Normalized difference } \\
\text { vegetation index }\end{array}$ & $\mathrm{NDVI}_{700}=\left(\rho_{800}-\rho_{700}\right) /\left(\rho_{800}+\rho_{700}\right)$ & $\begin{array}{l}\text { Gitelson and Merzlyak } \\
(1994 a, b)\end{array}$ \\
\hline Simple ratio index & $\mathrm{SR}_{700}=\rho_{750} / \rho_{700}$ & $\begin{array}{l}\text { Gitelson and Merzlyak } \\
(1996,1997), \\
\text { Boegh et al. (2012) }\end{array}$ \\
\hline Weighted simple ratio & $\mathrm{wSR}=\rho_{860} /\left(\rho_{708} \times \rho_{550}\right)$ & $\begin{array}{l}\text { Datt (1998), } \\
\text { Gitelson et al. (2003) }\end{array}$ \\
\hline $\begin{array}{l}\text { Normalized difference } \\
\text { vegetation index }\end{array}$ & $\mathrm{NDVI}_{680}=\left(\rho_{800}-\rho_{680}\right) /\left(\rho_{800}+\rho_{680}\right)$ & Blackburn (1998) \\
\hline $\begin{array}{l}\text { Modified chlorophyll } \\
\text { absorption reflectance index }\end{array}$ & $\operatorname{MCARI}=\left[\left(\rho_{700}-\rho_{670}\right)-0.2\left(\rho_{700}-\rho_{550}\right)\right]\left[\rho_{700} / \rho_{670}\right]$ & Daughtry et al. (2000) \\
\hline $\begin{array}{l}\text { Modified red edge simple } \\
\text { ratio }\end{array}$ & $\mathrm{mSR}=\left(\rho_{750}-\rho_{445}\right) /\left(\rho_{705}-\rho_{445}\right)$ & Sims and Gamon (2002) \\
\hline Modified red edge NDVI & $\mathrm{mNDVI}=\left(\rho_{750}-\rho_{705}\right) /\left(\rho_{750}+\rho_{705}-2 \rho_{445}\right)$ & Sims and Gamon (2002) \\
\hline MERIS total chlorophyll index & MTCI $=\left(\rho_{750}-\rho_{710}\right) /\left(\rho_{710}-\rho_{680}\right)$ & $\begin{array}{l}\text { Dash and Curran (2004), } \\
\text { Rossini et al. (2012) }\end{array}$ \\
\hline $\begin{array}{l}\text { Reciprocal-based simple } \\
\text { ratio index }\end{array}$ & $\mathrm{rSR}_{705}=\left(\frac{1}{\rho_{705}}-\frac{1}{\rho_{780}}\right) \times \rho_{780}=\left(\rho_{780} / \rho_{705}\right)-1$ & Gitelson et al. (2006) \\
\hline Triangular chlorophyll index & $\mathrm{TCI}=1.2\left(\rho_{700}-\rho_{550}\right)-1.5\left(\rho_{670}-\rho_{550}\right)\left(\rho_{700} / \rho_{670}\right)^{0.5}$ & Haboudane et al. (2008) \\
\hline Simple ratio index & $\mathrm{SR}_{775}=\rho_{708} / \rho_{775}$ & Féret et al. (2011) \\
\hline $\begin{array}{l}\text { Normalized difference } \\
\text { vegetation index }\end{array}$ & $\mathrm{NDVI}_{712}=\left(\rho_{780}-\rho_{712}\right) /\left(\rho_{780}+\rho_{712}\right)$ & Féret et al. (2011) \\
\hline Triangular greenness index & $\mathrm{TGI}=-0.5\left[190\left(\rho_{670}-\rho_{550}\right)-120\left(\rho_{670}-\rho_{480}\right)\right]$ & Hunt et al. $(2011,2013)$ \\
\hline Simple ratio stress index & $\mathrm{SR}_{760}=\rho_{695} / \rho_{760}$ & Carter (1994) \\
\hline Simple ratio stress index & $\mathrm{SR}_{420}=\rho_{695} / \rho_{420}$ & Carter (1994) \\
\hline $\begin{array}{l}\text { Simple ratio index broadband } \\
\text { red edge }\end{array}$ & $\mathrm{CI}_{\text {red edge }}=\left(\rho_{760-800} / \rho_{690-710}\right)-1$ & Gitelson et al. (2009) \\
\hline
\end{tabular}

100 billion tons of carbon is fixed annually into organic compounds by photosynthetic organisms (Nobel, 2005). The forest, a complex ecosystem of numerous trees, shrubs, savanna, and lichens, uptakes carbons for vegetation metabolism, and thus it makes a positive net primary production of biomass carbon.

Foliar chlorophyll concentration (shortened as Chls) has always been one of the important issues of research using vegetation remote sensing techniques in last 2 decades. As a consequence, a number of spectral indices were developed for foliar Chls estimation. Table 1 lists some of the chlorophyll indicators that have been examined by Vogelmann et al. (1993), Elvidge and Chen (1995), Blackburn and Ferwerda (2008), Ustin et al. (2009), Féret et al. (2011), and Hunt et al. (2013). Those indices integrate a couple of specific signatures of visible and near-infrared bands, for example, the reflectance at $445,550,680,700,705,710,720,750,780$, $800,860 \mathrm{~nm}$ for foliar Chls estimation.

Typical reflectance of vegetation in the visible-infrared region will increase as water deficit occurs (Knipling, 1970; Gausman and Allen, 1973; Gausman et al., 1982; Hunt and Rock, 1989; Carter, 1991 and 1993; Ceccato et al., 2001; Zygielbaum et al., 2009; Lin et al., 2012). As leaves dehydrate or vegetation suffers water stress, leaf water potential becomes increasingly negative and the rate of photosynthesis is reduced (Nilsen and Orcutt, 1996; Montagu and Woo, 1999; Keenan et al., 2009; Lavoir et al., 2009) because water deficit can cause chlorophyll degradation and thus significantly decreases foliar chlorophyll concentration (Kirnak et al., 2001; Pirzad et al., 2011; Desotgiu et al., 2012; Ghorbanli et al., 2013). Specifically, the magnesium ion $\left(\mathrm{Mg}^{2+}\right)$ of the chlorophyll will be removed. As a result, chlorophyll 
becomes pheophytin (chlorophyll without $\mathrm{Mg}^{2+}$ ) and inactivates the photochemical reaction (Kaoau et al., 2007; Schelbert et al., 2009; Weber et al., 2009); furthermore leaves decrease the absorptance of blue and red light while increasing the reflectance at the corresponding wavelength bands. This underpins the first basic assumption of this study that a spectral index that effectively integrates the reflectance at the blue and red bands, at which the light specifically absorbed by chlorophyll is only used for plant photosynthesis, is better for foliar Chls estimation than the indices (listed in Table 1) that use other than the blue and red bands.

The dynamics of pigment concentrations are diagnostic of a range of plant physiological properties and processes (Blackburn, 2007). A suitable chlorophyll index can offer useful information for estimating the gross productivity of a terrestrial ecosystem (Nave et al., 2011) and even for understanding dust storm events (Tan et al., 2011). In order to address the effects of global climate changes, it is necessary to continuously update the prediction of forest carbon sequestration and the net primary productivity of terrestrial ecosystem. Traditional methods of using a spectrophotometer and/or fluorometer in ground leaf liquids operate on the light absorption of leaf in a laboratory setting. Determining foliar Chls with this technique is a standard measurement. In recent years, chlorophyll meters have offered a fast and convenient alternative for foliar Chls measurement. The Minolta SPAD 502 is used for a wide variety of leaf chlorophyll and nitrogen estimation by measuring the amount of light transmittance and absorptance in an easy and non-destructive way (Takebe et al., 1990; Ma et al., 1995; Blackmer and Schepers, 1995; Cate and Perkins, 2003; Read et al., 2003; Rowland et al., 2004; Hawkins et al., 2009; Rascher et al., 2009; Boegh et al., 2012). Nevertheless, it will be extremely hard work to extend the result of traditional methods to field study because such a single leaf measurement will be useless (due to no connection) for up-scaling the Chls and/or the fraction of absorbed photosynthetically active radiation (Gond et al., 1999) for the levels at tree crown or stand canopy.

In addition, since a chlorophyll meter works based on the sensing of leaves absorptance and transmittance, the reading of chlorophyll concentration will be affected by changes in transmittance as if there is a water deficit in leaves. On the other hand, the use of the relationship between the chlorophyll concentration and the readings of the chlorophyll meter may not accurately observe the chlorophyll variations due to physiological stresses. Because remote sensing only uses the reflectance to differentiate materials and/or discern the properties of targets, it therefore can offer good opportunity to indirectly determine foliar Chls. Therefore, the second assumption of this study is based on the fact that foliar reflectance at the photosynthesis wavebands is a better representative of foliar biochemical spectra than single leaf transmittance (handheld chlorophyll meter) in a non-destructive detection base.

Many studies indicated that the spectral characteristics of red edge (RE) and green peak (GP) are directly or indi- rectly correlated to the level of leaf chlorophyll (Horler et al., 1983; Curran et al., 1990; Filella and Peñuelas, 1994; Pinar and Curran, 1996; Jongschaap and Booij, 2004; Mutanga and Skidmore, 2007) and can provide a method to distinguish between water and nutrient stress (Estep and Carter, 2005); they should be helpful in the prediction of leaf chlorophyll concentration. However, little research has examined the effectiveness of remote sensing models in the estimation chlorophyll content of both fresh and water-stressed leaves. We therefore proposed as a major goal of our study to develop a spectral index which could effectively integrate the reflectance of the photosynthetic-related spectra for leaf chlorophyll determination in a reliable non-destructive way for field application.

Briefly, the null hypotheses specified as follows will be examined in this paper.

H01: The reflectance at the wavelengths (e.g., 663, 645, 455 , and $426 \mathrm{~nm}$, that is, ChlsPn variables) directly absorbed by chlorophyll for photosynthesis is significantly and negatively related to foliar Chls with respect to variation of leaf water content.

H02: Reflectance-based spectral indices derived from $\mathrm{ChlsPn} / \mathrm{RE} / \mathrm{GP}$ variables are closely related to foliar Chls and can make better estimations of Chls than other indices without ChlsPn variables in respect to different degrees of waterstressed conditions.

H03: The determination of foliar Chls using the transmittance-based meter (e.g., SPAD chlorophyll meter) is insensitive to leaf water content.

\section{Materials and methods}

There were two independent experiments adopted to develop the foliar chlorophyll concentration models. The first was the chlorophyll-reflectance experiment from which training leaf samples were collected for reflectance measurement and chlorophyll determination, and the second was the chlorophyll SPAD experiment in which a new set of leaf samples was collected independently for SPAD measurement and chlorophyll concentration determination. Finally, additional leaf samples were used as a test data set for further validation of those models developed based on foliar reflectance experiment or SPAD absorptance experiment.

A hardwood species, namely Camphor tree (Cinnamomum camphora (Linn.) Seib), was selected for experiments. Leaf samples sized around $6-8 \mathrm{~cm}$ long by $3-4 \mathrm{~cm}$ wide were collected from the campus of the National Chiayi University in Taiwan. The authors intended to have samples collected in a wide range of pigment concentrations to meet the needs of this study. According to the ground inventory, we collected samples to meet leaf colors including dark green, light green, yellowish green, red, and dark red for laboratory experiments. Leaf samples of the data sets for chlorophyllreflectance experiment and chlorophyll SPAD experiment is 
50 and 45 , respectively, and the additional evaluation data set is 70 leaves.

\subsection{Data acquisition}

\subsubsection{Determination of foliar chlorophyll contents}

Wellburn (1994) demonstrated that the chlorophyll concentration of leaf pigments could be determined by acetone, chloroform, dimethylformamide, and dimethyl-sulfoxide with spectrophotometer analysis. Concentrations of the tested foliar chlorophyll were extracted from the $80 \%$ acetone solution and determined spectrophotometrically using a Hitachi U-2000 spectrophotometer following the method of Arnon (1949). Concentrations of chlorophyll $a$ (Chl $a$ ) and chlorophyll $b(\mathrm{Chl} b)$ are determined using Eqs. (1) and (2) where $D_{\lambda}$ stands for the absorptance at the specific wavelength $\lambda$, and where $V$ and $W$ represent the volume of ground leaf-acetone liquid ( $\mathrm{ml})$ and the fresh weight $(\mathrm{g})$ of the ground leaf, respectively. Total chlorophyll concentration, Chls, was expressed as milligrams of chlorophyll per gram of fresh leaf weight $\left(\mathrm{mg} \mathrm{g}^{-1}\right)$ and can be derived by summing up the values of $\mathrm{Chl} a$ and $\mathrm{Chl} b$.

$$
\begin{aligned}
& \text { Chl } a=\left(12.7 \times D_{663}-2.69 \times D_{645}\right) \times(V / 1000 W) \\
& \text { Chl } b=\left(22.9 \times D_{645}-4.68 \times D_{663}\right) \times(V / 1000 W)
\end{aligned}
$$

\subsubsection{Foliar reflectance measurement}

Spectral data were obtained from the FieldSpec Pro FR spectroradiometer manufactured by Analytical Spectral Devices (ASD). This instrument measures spectra over a spectral range of $350-2500 \mathrm{~nm}$ and offers $1 \mathrm{~nm}$ wide narrowband spectral data. Specifically, the full-width at half-maximum (FWHM) spectral resolution of the FieldSpec Pro FR spectroradiometer is $3 \mathrm{~nm}$ for the region $350-1000$ and $10 \mathrm{~nm}$ for the region 1000-2500 $\mathrm{nm}$ (Hatchell, 1999) which meets the nominal sampling and resolution requirements for hyperspectral remote sensing applications (Curtiss and Goetz, 1994).

Procedures to gathering spectra involve optimizing the integration time (typically set at $17 \mathrm{~ms}$ ), providing foreoptic information, recording dark current, collecting Spectralon reference radiance, and then obtaining target radiance. A $25^{\circ}$ field-of-view (FOV) foreoptic which connected ASD spectroradiometer and the computer control system was mounted $35 \mathrm{~cm}$ above and leveled at a tripod on the top of leaf samples. As a result, a pixel size of $1.5 \mathrm{~cm}$ was determined as optimal. A black cloth was used to cover the platform to avoid the influence of background reflection. Two light sources were face to face mounted at an elevation angle of $45^{\circ}$ and $1 \mathrm{~m}$ away from the sample. The target reflectance is determined as the ratio of the energy reflected off the target (target radiance) to energy incident on the reference Spectralon (reference radiance). For each measurement, the radiance was taken with spectrum averaging set to 15 and then filtered using a median filter (Hatchell, 1999; Lin et al., 2012).

Leaves reflectance spectra were measured in a laboratory with an artificial illuminator (USHIO jc 14.5V-50WC) before the leaves grinding process for chlorophyll determination. The ASD spectroradiometer collects one nanometer resolution hyperspectral data. A first derivative transformation of the reflectance spectra (Novo et al., 1995; Dawson et al., 1998) was applied to calculate the slope values of the foliar reflectance spectra, also known as first derivative spectra (FDS), and to determine the red edge position. This position has the largest FDS value which indicates the maximum change in the slope of the reflectance spectra per unit change in wavelength. Red edge position generally moves toward the longer wavelength if the FDS become larger which is a result of high chlorophyll concentrations in leaves. Leaf color is generally applied to visually diagnose foliar chlorophyll or health status. Green peak is supposed to be the main syndrome of foliar greenness and probably could offer potential value in the foliar Chls estimation. Green peak position is determined if the FDS value equals to zero.

\subsubsection{Implement of spectral and chlorophyll measurement of fresh and water-stressed leaves}

Relative water content (RWC) of leaves is commonly used to assess the water status of plants in tree physiology research. It has been applied to describe the status of leaf water stress in remote sensing (Pu et al., 2003; Lin et al., 2012) and is therefore used in this study. Fresh leaf samples were first detached, measured for fresh weight (FW), and then spectral reflectance data were immediately collected. Leaf samples were then left to dry naturally in an air-conditioned room at $26^{\circ} \mathrm{C}$ with air circulated with a fan. Measurements of leaf weight and reflectance were made every $2 \mathrm{~h}$ during the drying process for $24 \mathrm{~h}$. After collecting the final drying leaf weight and spectra, the leaf samples were oven-dried and the absolute dry weight (WD) was recorded. Finally, the RWC of fresh leaves and drying leaves were determined using Eq. (3). We further refer to this experiment as the pilot experiment.

$\mathrm{RWC}=\frac{\mathrm{FW}-\mathrm{WD}}{\mathrm{FW}} \times 100$

The first experiment is a chlorophyll-reflectance experiment in which a total of 50 leaves were first used for spectral measurement and then ground for chlorophyll concentration determination. The second experiment is the chlorophyll SPAD experiment which was designed for exploring the relationship of the SPAD readings and leaf chlorophyll contents. A chlorophyll meter SPAD-502 (Konica Minolta Sensing, Inc.) was used for quick measurements of the chlorophyll content. In this experiment, we had 45 samples which were first measured by SPAD readings then ground and dissolved in acetone solution for chlorophyll concentration determination. Data collected from these two experiments were used 
for correlation and regression analysis to derive the relationships of chlorophyll-reflectance spectra and chlorophyll SPAD readings. The third experiment is a validation experiment. An additional 70 leaf samples were first detached, and measurements of their weight were recorded along with SPAD and reflectance of fresh leaves, and then left to dry naturally in the same environmental conditions as the pilot experiment. $24 \mathrm{~h}$ later, spectral measurements were implemented immediately after obtaining the weight and SPAD measurements for every leaf samples. A small portion, a circle with a diameter of $1.5 \mathrm{~cm}$ (set $\left.W_{\mathrm{s}}\right)$ of each of the leaf samples (set $W_{\text {total }}$ ) was taken for the determination of foliar Chls in the acetone solution, and the another part of each of the leaf samples was oven-dried to get the dry weight for the determination of leaf RWC based on the weight ratio of $W_{\mathrm{s}}$ and $W_{\text {total }}$.

\subsection{Correlation analysis and regression analysis}

A correlation analysis was applied to determine the correlation coefficient $(r)$ between the foliar chlorophyll concentration and its reflectance. All of the coefficients were further tested using the Student's $t$ statistic: $t=$ $r \sqrt{(n-2) /\left(1-r^{2}\right)} \sim t_{\alpha / 2, n-2}$ to examine whether it is statistical meaningful for diagnosing foliar chlorophyll status.

Arnon (1949) demonstrated that chlorophyll $a$ and chlorophyll $b$ have particular absorption features in the blue and red spectral region in the acetone solution. Specifically, Chl $a$ and $\mathrm{Chl} b$ have two absorption peaks for photosynthesis at the wavelengths of 426 and $663 \mathrm{~nm}$, and 455 and $645 \mathrm{~nm}$, respectively. The absorption peaks of Chl $a$ and $\mathrm{Chl} b$ in other solvents, such as chloroform, shift a little from the predefined wavelength (Wellburn, 1994). Since the chlorophyll was determined by using the acetone solvent, the spectral reflectance at those four specific wavelengths, i.e., $\rho_{663}, \rho_{645}$, $\rho_{445}$, and $\rho_{426}$ are called ChlsPn variables; the chlorophyllrelated spectra such as the position and reflectance of the green peak feature $\left(\lambda_{\mathrm{Gmax}}\right.$ and $\left.\rho_{\mathrm{Gmax}}\right)$ and the red edge feature $\left(\lambda_{\text {REP }}\right.$ and $\left.\rho_{\text {REP }}\right)$ are called GP variables and RE variables. A transformation of two key spectral features can be integrated by simple ratio $\left(\rho_{i} / \rho_{j}\right)$, simple difference $\left(\rho_{i}-\right.$ $\left.\rho_{j}\right)$, and normalized difference $\left(\rho_{i}-\rho_{j}\right) /\left(\rho_{i}+\rho_{j}\right)$ methods to derive a new spectral index for remote sensing analysis. A new transformation, the slope index (SI), was defined as the ratio of the spectral difference and the distance of any two key features. That is $\mathrm{SI}=\left(\rho_{i}-\rho_{j}\right) /\left(\left|\lambda_{i}-\lambda_{j}\right|\right)$. This index integrates two spectral reflectance values based on their spectral curve (or spectral behavior) into a standardized index value and potentially can reduce the influence caused by background reflection and various albedo. The original form of the variables ChlsPn, GP, and RE and their derived spectral indices (Eqs. 6-21) were used as variables (shown in Table 2) in regression analysis. Reflectance-based empirical Chls models were than validated to examine the hypotheses of this study.
In the regression analysis of reflectance-based models, the dependent variable is the natural-logarithm-transformed foliar Chls, denoted as lnChls. The transformation is used to stabilize the constant variance of the predicted error term. Also, the independent variables are the ChlsPn variables, the GP variables, the RE variables, and/or their derived spectral indices. The statistics such as the coefficient of determination $\left(R^{2}\right)$, the prediction error sum of squares (PRESS), and the standard error of estimates $(\operatorname{SE}(Y))$ were used to measure the model adequacy. In the regression analysis of SPAD-based chlorophyll model, the SPAD readings and acetone-extracted chlorophyll was set to be the regressor variable and the dependent variable, respectively; the fitted model is named as the absorptance-based chlorophyll model.

\subsection{Validation of reflectance-based and absorptance-based chlorophyll empirical models}

The reflectance spectra and SPAD readings collected by the third experiment were input to the absorptance-based model and the reflectance-based models to get the estimates of the foliar chlorophyll concentration; each of the estimates was then assessed by the acetone-method-determined chlorophyll contents. In the prediction assessment, the formula of root mean squared error (RMSE) and mean absolute error (MAE) are listed in Eqs. (4) and (5) and applied to demonstrate how the estimator differs from the measured value of the quantity being estimated. RMSE has the same units $\left(\mathrm{mg} \mathrm{g}^{-1}\right)$ as the quantity being estimated, and MAE is presented in percentage, indicating a relative degree of the estimation differs from the observation. In Eqs. (4) and (5), $n$ is the number of samples, $y$ and $\hat{y}$ represent the observed and predicted value, respectively.

$$
\begin{aligned}
\text { RMSE } & =\sqrt{\frac{\sum_{i=1}^{n}\left(y_{i}-\hat{y}_{i}\right)^{2}}{n}} \\
\text { MAE } & =\frac{1}{n}\left[\sum_{i=1}^{n} \frac{\operatorname{abs}\left(y_{i}-\hat{y}_{i}\right)}{y_{i}} \times 100 \%\right]
\end{aligned}
$$

\section{Results}

\subsection{Reflectance spectra of fresh and water-stressed leaf}

Figure 1a shows the spectral behavior of the fresh and waterstressed leaves of camphor trees. RWC of the leaf sample varied from 51 to $5 \%$. Four aspects could be pointed out about the difference of reflectance spectra between fresh and water-stressed leaves. First, reflectance spectra in the visibleinfrared region behaved like a general reflectance curve of fresh green leaves while the curve lifts up as the RWC decreased. Second, the green peak of the reflectance curves was always clearly visible and the slope from the peak at 
Table 2. The meaning and the formula of some extended spectral indices derived from the ChlsPn variables, red edge, and green peak variables.

\begin{tabular}{|c|c|c|}
\hline Regressor names & Meaning and mathematical formula & \\
\hline $\begin{array}{l}\text { RDI group } \\
\operatorname{RDI}_{a}\end{array}$ & $\begin{array}{l}\text { Reflectance difference index of two spectral features from ChlsPn, red edge, and green peak. } \\
\text { RDI derived based on the two absorption peaks of chlorophyll } a \text { at } 663 \mathrm{~nm} \text { and } 426 \mathrm{~nm} \text {. } \\
\operatorname{RDI}_{a}=\rho_{663}-\rho_{426}\end{array}$ & (6) \\
\hline $\mathrm{RDI}_{b}$ & $\begin{array}{l}\text { RDI derived based on the two absorption peaks of chlorophyll } b \text { at } 645 \mathrm{~nm} \text { and } 455 \mathrm{~nm} \text {. } \\
\operatorname{RDI}_{b}=\rho_{645}-\rho_{455}\end{array}$ & (7) \\
\hline $\mathrm{RDI}_{\rho_{\mathrm{REP}}-\rho_{\mathrm{Gmax}}}$ & $\begin{array}{l}\text { RDI derived based on the red edge and green peak position. } \\
\operatorname{RDI} \rho_{\text {REP }}-\rho_{\mathrm{Gmax}}=\rho_{\mathrm{REP}}-\rho_{\mathrm{Gmax}}\end{array}$ & $(8)$ \\
\hline $\begin{array}{l}\text { SI group } \\
\mathrm{SI}_{a}\end{array}$ & $\begin{array}{l}\text { Slope index of two spectral features from ChlsPn, red edge, and green peak. } \\
\text { SI determined using the two absorption peaks of chlorophyll } a \text {. } \\
\mathrm{SI}_{a}=\left(\rho_{663}-\rho_{426}\right) /\left(\lambda_{663}-\lambda_{426}\right)\end{array}$ & (9) \\
\hline $\mathrm{SI}_{b}$ & $\begin{array}{l}\text { SI determined using the two absorption peaks of chlorophyll } b \text {. } \\
\mathrm{SI}_{b}=\left(\rho_{645}-\rho_{455}\right) /\left(\lambda_{645}-\lambda_{455}\right)\end{array}$ & $(10)$ \\
\hline $\mathrm{SI}_{\rho_{\mathrm{REP}} \mid \rho_{\mathrm{Gmax}}}$ & $\begin{array}{l}\text { SI determined using the red edge and green peak features. } \\
\mathrm{SI}_{\rho_{\mathrm{REP}} \mid \rho_{\mathrm{Gmax}}}=\left(\rho_{\mathrm{REP}}-\rho_{\mathrm{Gmax}}\right) /\left(\lambda_{\mathrm{REP}}-\lambda_{\mathrm{Gmax}}\right)\end{array}$ & $(11)$ \\
\hline $\begin{array}{l}\text { NDI group } \\
\mathrm{NDI}_{a}\end{array}$ & $\begin{array}{l}\text { Normalized difference index of two spectral features from ChlsPn, red edge, and green peak. } \\
\mathrm{NDI}_{a}=\left(\rho_{663}-\rho_{426}\right) /\left(\rho_{663}+\rho_{426}\right)\end{array}$ & (12) \\
\hline $\mathrm{NDI}_{b}$ & $\mathrm{NDI}_{b}=\left(\rho_{645}-\rho_{455}\right) /\left(\rho_{645}+\rho_{455}\right)$ & (13) \\
\hline $\mathrm{NDI}_{R E P R D I b}$ & $\mathrm{NDI}_{\mathrm{REPRDI} b}=\left(\rho_{\mathrm{REP}}-\mathrm{RDI}_{b}\right) /\left(\rho_{\mathrm{REP}}+\mathrm{RDI}_{b}\right)$ & (14) \\
\hline $\mathrm{NDI}_{\text {REPGmax }}$ & $\mathrm{NDI}_{\mathrm{REPGmax}}=\left(\rho_{\mathrm{REP}}-\rho_{\mathrm{Gmax}}\right) /\left(\rho_{\mathrm{REP}}+\rho_{\mathrm{Gmax}}\right)$ & $(15)$ \\
\hline RI group & Ratio Index of two spectral features from ChlsPn, red edge, and green peak. & \\
\hline $\mathrm{RI}_{a}$ & $\mathrm{RI}_{a}=\rho_{663} / \rho_{426}$ & (16) \\
\hline $\mathrm{RI}_{b}$ & $\mathrm{RI}_{b}=\rho_{645} / \rho_{455}$ & $(17)$ \\
\hline 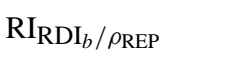 & $\mathrm{RI}_{\mathrm{RDI}_{b} / \rho_{\mathrm{REP}}}=\mathrm{RDI}_{b} / \rho_{\mathrm{REP}}$ & (18) \\
\hline $\mathrm{RI}_{\mathrm{RDI}_{b} / \lambda_{\mathrm{REP}}}$ & $\mathrm{RI}_{\mathrm{RDI}_{b} / \lambda_{\mathrm{REP}}}=\mathrm{RDI}_{b} / \lambda_{\mathrm{REP}}$ & $(19)$ \\
\hline $\mathrm{RI}_{\rho_{\mathrm{Gmax}}} / \rho_{\mathrm{REP}}$ & $\mathrm{RI}_{\rho_{\mathrm{Gmax}} / \rho_{\mathrm{REP}}}=\rho_{\mathrm{Gmax}} / \rho_{\mathrm{REP}}$ & (20) \\
\hline RISPAD & $\mathrm{RI}_{\mathrm{SPAD}}=\rho_{650} / \rho_{940}$ & $(21)$ \\
\hline
\end{tabular}

green region to the lowest point at red region was significantly decreased when RWC is less than $30 \%$. Third, the significant water absorption valleys could be seen at the spectral regions centered at 1450 and $1910 \mathrm{~nm}$. The depth and the area of the absorption valley are negatively closely related to leaf RWC (Lin et al., 2012). Finally, a water-stressed leaf reflectance peaked at around $2000 \mathrm{~nm}$ as the RWC was less than or equal to $16 \%$. Although the absorption feature in the infrared region (2000-2200 nm) is possibly due to the dry matter constituents (such as protein, lignin, and cellulose) (Cheng et al., 2011), this particular phenomenon is probably related to physiological reactivity. It should be worthwhile to explore in further studies. Figure $1 b$ shows the first derivative of reflectance in the visible region of a sample leaf. The red edge and green peak of the sample leaf were detected at around 701-697 and 540-535 $\mathrm{nm}$ respectively. It was observed that a small shift from longer to shorter wavelengths happened as RWC changed from 51 to $5 \%$. Even though the shifts were not very significant, it still indicated that the foliar Chls would decrease if the water content of leaves decreased. This phenomenon agree with the one addressed by Kirnak et al. (2001), Pirzad et al. (2011), Desotgiu et al. (2012), and Ghorbanli et al. (2013).

\subsection{Response of leaf reflectance to variations in leaf chlorophyll concentration}

Figure 2a demonstrates the reflectance spectra over the visible-infrared wavebands of the fresh leaves in the first 
(a)

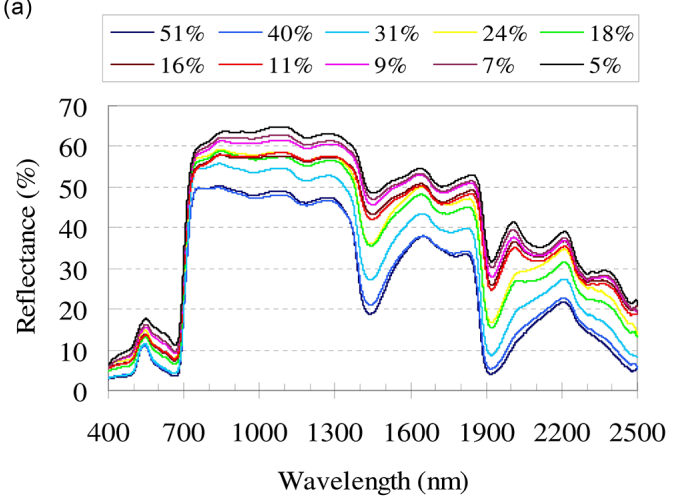

(b)
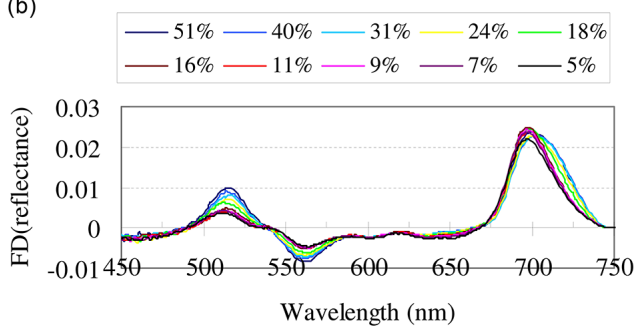

Wavelength (nm)

Figure 1. Foliar reflectance spectra of Cinnamomum camphora. (a) Spectral curves showed the reflectance variation of visible-infrared bands due to the changes of water content. (b) An example of the association between the relative water content in fresh and water-stressed leaves and the green peak and red edge spectra features.

(a)

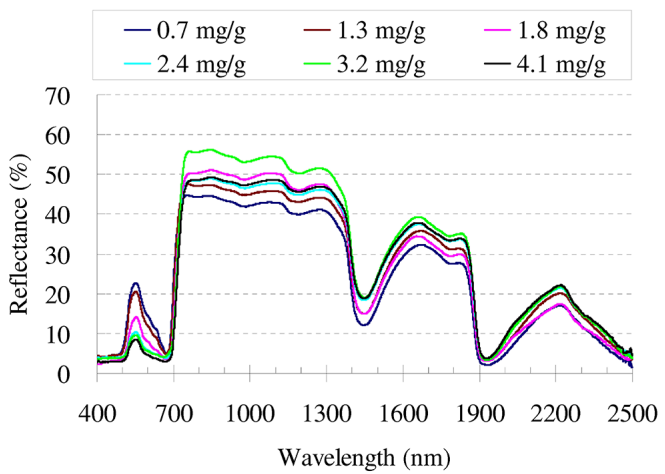

(b)

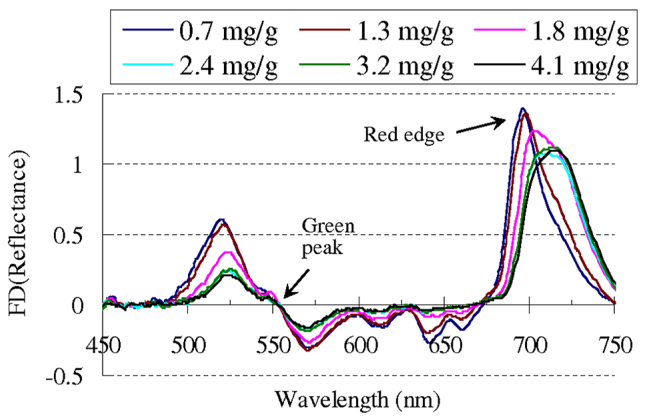

Figure 2. Foliar reflectance spectra of Cinnamomum camphora. (a) Spectral curves showed the reflectance variation of visible-infrared bands due to the changes of foliar chlorophyll concentration. (b) Association between the chlorophyll concentration and the green peak and red edge spectra of fresh leaves.

experiment. The Chls of these samples ranged from 0.7 to $4.1 \mathrm{mg} \mathrm{g}^{-1}$. An important feature that was observed showed that the change of reflectance in the visible region behaves obviously different from the one in the infrared region due to changes of foliar Chls. Leaves with smaller Chls showed a higher reflectance in the visible portion of the spectrum. This is very similar to the increase of the reflectance curve as leaves are under water-stressed conditions. On the contrary, a leaf with higher Chls demonstrated higher reflectance in the infrared area, which is not always consistent with the increase of foliar Chls among all of the samples.

The blue drop and the red drop in the visible region are due to photons being absorbed by the chlorophylls $a$ and $b$ in the photosynthesis process (Emerson and Lewis, 1943; Hopkins and Hüner, 2004). It indicates that a sharp decrease happened to the gradient between these two points (that is, the gradient) for the leaf with higher value of Chls. In other words, a leaf whose reflectance in visible region will decrease (level down), the gradient will also decline as it is maturing. As- sociations between the green peak and the red edge features and values of foliar Chls are shown in Fig. 2b, which indicates that the green peaks and the red edge occur at wavelengths around 554-557 and 694-715 nm, respectively. As foliar Chls decreased, the red edge position moves toward shorter wavelengths, the same trend being observed for the blue edge.

\subsection{Relationship of chlorophyll concentration and visible-infrared reflectance spectra}

Leaf spectral reflectance $\left(\rho_{\lambda}\right)$ is correlated to foliar Chls. Figure 3 demonstrates the generalized visible-infrared spectra of Cinnamomum camphora leaves and associated with the corresponding correlogram of Pearson's correlation coefficients, denoted as $r\left(\mathrm{Chls}, \rho_{\lambda}\right)$ a correlation coefficient of the foliar chlorophyll concentration and the reflectance at wavelength $\lambda$. A negative coefficient $r\left(\mathrm{Chls}, \rho_{\lambda}\right)<0$ was found in the visible region while a positive coefficient $r\left(\mathrm{Chls}, \rho_{\lambda}\right)>0$ was found in the infrared region. 


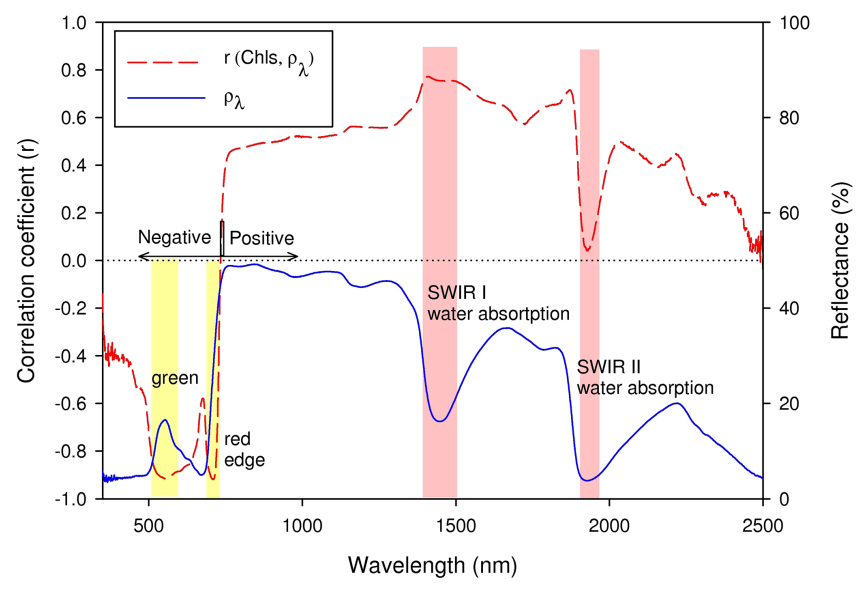

Figure 3. Generalized reflectance spectra of Cinnamomum camphora leaf (solid line) and trends of the corresponding correlation coefficients (dashed line) between the concentration of total chlorophyll and reflectance in the visible-infrared wavelength region. Results derived from the training data set, the 50 leaf samples.

Most of the reflectance values between 350-2500 nm have proven to be significantly linearly related to foliar Chls based on the Student's t statistic $t=r \sqrt{(n-2) /\left(1-r^{2}\right)} \sim$ $t_{\alpha / 2, n-2}$. Exceptions are the sub-regions 730-741, 19051970 , and $2408-2500 \mathrm{~nm}$. Reflectance of the bands at green sub-region 530-580 $\mathrm{nm}$ and red edge sub-region 700-716 $\mathrm{nm}$ are valuable because the absolute value of their $r\left(\mathrm{Chls}, \rho_{\lambda}\right)$ are greater than $0.90(P<0.01)$. Although vegetation is proven to use the light energy in blue (PS I) and red (PS II) wavelengths for photosynthesis, the reflectance spectra appears different than the absorption spectra.

Infrared reflectance is positively related to foliar Chls. It is observed that in the first sub-region of shortwave infrared, a dramatic drop of reflectance curve happened in the water absorption area (1395-1504 nm, denoted as SWIR I), with a value of $r\left(\mathrm{Chls}, \rho_{\lambda}\right)$ around 0.75 . In the second sub-region of shortwave infrared (1905-1970 nm, denoted as SWIR II), the reflectance is almost independent of foliar Chls because the value of $r\left(\mathrm{Chls}, \rho_{\lambda}\right)$ is almost identical to zero, as indicated by the Student's $t$ test results.

\section{Discussions}

\subsection{Reflectance-based empirical models for the estimation of total chlorophyll content}

\subsubsection{Adequacy comparison among the models with prototype variables}

Recall that a measured value of foliar chlorophyll is determined by the spectrophotometrical method. This method uses the absorptance peaks of blue spectra at 426 and $455 \mathrm{~nm}$ and the absorptance peaks of red spectra at 645 and $663 \mathrm{~nm}$.
The reflectance of those specific wavelengths, i.e., $\rho_{426}$, $\rho_{455}, \rho_{645}$, and $\rho_{663}$ are named as the ChlsPn variables, the red edge characteristics $\rho_{\text {REP }}$ and $\lambda_{\text {REP }}$ are named as red edge variables, and the green peak characteristics $\rho_{\mathrm{Gmax}}$ and $\lambda_{\mathrm{Gmax}}$ are named as green peak variables hereafter in this paper.

Based on the fundamentals of remote sensing, a target will reflect smaller amount of incident energy if it absorbs most of the incident energy. Figure $4 \mathrm{a}-\mathrm{d}$ shows that foliar chlorophyll concentration is negatively related to the reflectance of the ChlsPn variables. It indicates that higher foliar chlorophyll concentration causes lower reflectance of the blue and red spectra. The models with one of the ChlsPn variables work like the spectrophotometric method. Figure $4 \mathrm{e}$ and $\mathrm{f}$ show that the chlorophyll concentration is positively linearly related to the red edge variables indicating a result similar to Curran et al. (1991). The adequacy statistics $R^{2}$, PRESS, and $\mathrm{SE}(Y)$ show that $\lambda_{\mathrm{REP}}$ is better than $\rho_{\mathrm{REP}}$ and even better than $\rho_{645}$ in the prediction of chlorophyll concentration. There are $89 \%$ of the Chls variation could be explained by $\lambda_{\text {REP }}$ while only $30 \%$ of the Chls variation could be explained by $\rho_{\text {REP }}$. This result agrees with the research of Mutanga and Skidmore (2007) and Reddy and Matcha (2010), who demonstrated that the red edge position is strongly negatively correlated with the foliar pigment concentration in plants. The reductions in Chls increased leaf reflectance at red spectral region and caused the red edge shift to shorter wavelengths. This agrees with conclusions of Carter (1993) and Carter and Knapp (2001). Though the Chls of training samples show a big variation, the green peak position $\left(\lambda_{\mathrm{Gmax}}\right)$ changes only in a very short span from 554 to $557 \mathrm{~nm}$. There is only $10 \%$ of Chls that could be explained by the variable $\lambda_{\mathrm{Gmax}}$ (Fig. 4g). The Chls is much better fitted by the reflectance of the green peak position $\left(\rho_{\mathrm{Gmax}}\right)$ with a negatively linear relationship (Fig. 4h). This model has adequacy very close to the model with the regressor $\lambda_{\text {REP }}$.

\subsubsection{Adequacy comparison among the models using a derived spectral index}

Figure 5 shows the relationship between the lnChls and the difference index or the slope index of red and blue absorption peaks by the prototype variables, and of the green peak and red edge variables. $\mathrm{RDI}_{a}$ and $\mathrm{SI}_{a}$ are negatively linearly related to lnChls while $\mathrm{SI}_{a}$ has a better model adequacy than $\mathrm{RDI}_{a}$ (Fig. 5a and b). It is observed that both predictors $\mathrm{RDI}_{b}$ and $\mathrm{SI}_{b}$ have an exponential decay relationship with the lnChls (Fig. 5c and d); the regression coefficient of the predictor is negative which means that a lower value of total chlorophyll concentration will be observed when having a higher value of $\mathrm{RDI}_{b}$ or $\mathrm{SI}_{b}$.

The predictors $\mathrm{RDI} \rho_{\rho_{\mathrm{REP}}-\rho_{\mathrm{G} \max }}$ and $\mathrm{SI}_{\rho_{\mathrm{REP}} \mid \rho_{\mathrm{G} \max }}$ work like a two-order polynomial function in the prediction of lnChls. These two models also have the same levels of the indicators of model adequacy (Fig. 5e and f). The coeffi- 

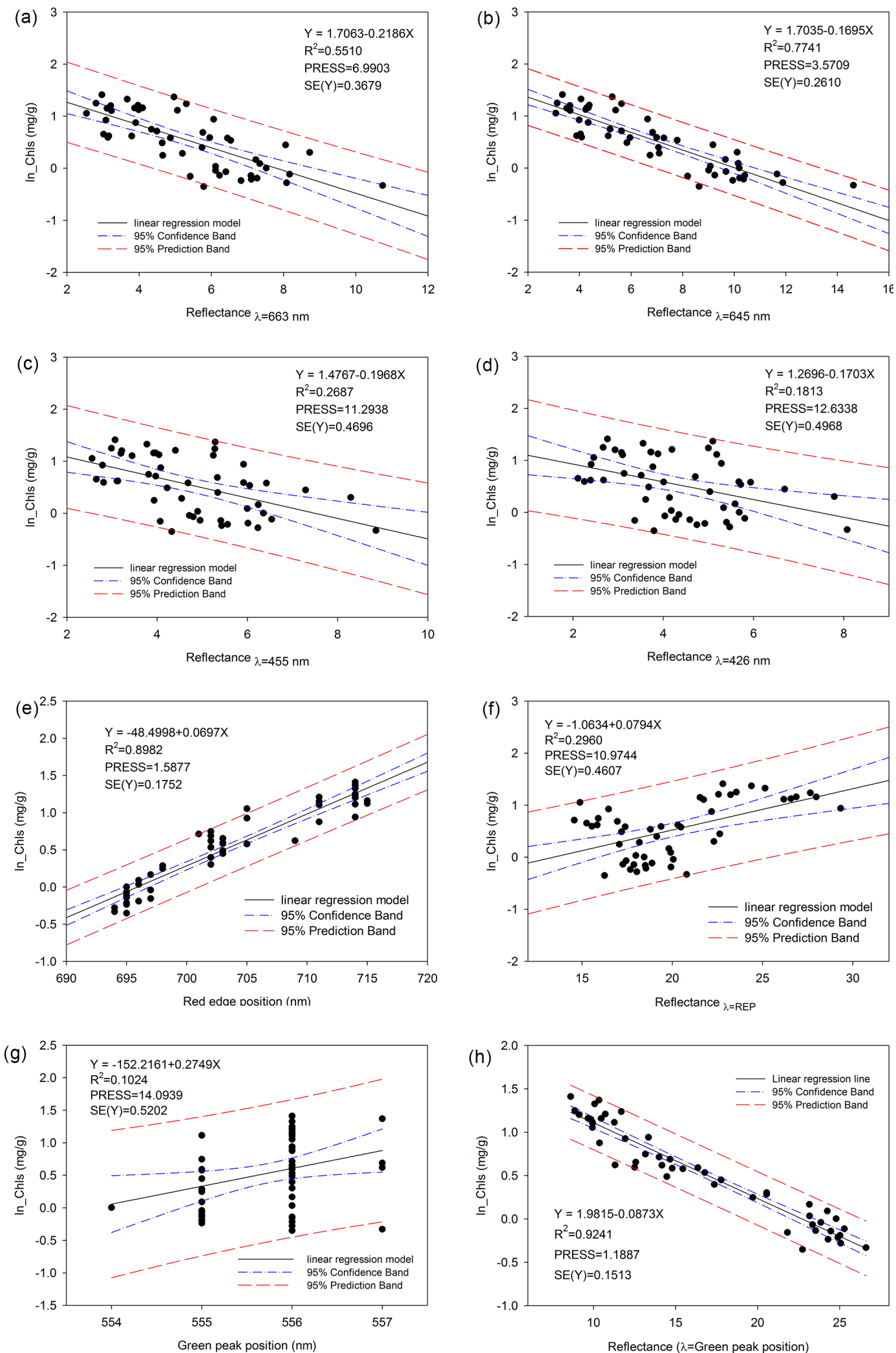

Figure 4. Reflectance-based empirical models with the ChlsPn/red edge/green peak variables for leaf total chlorophyll content estimation. 
(a)

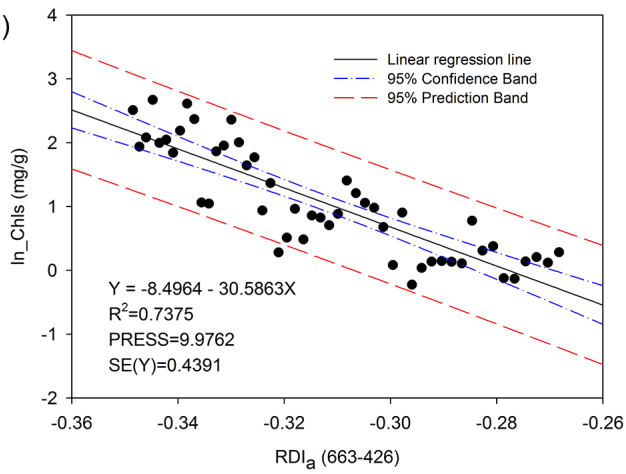

(c)

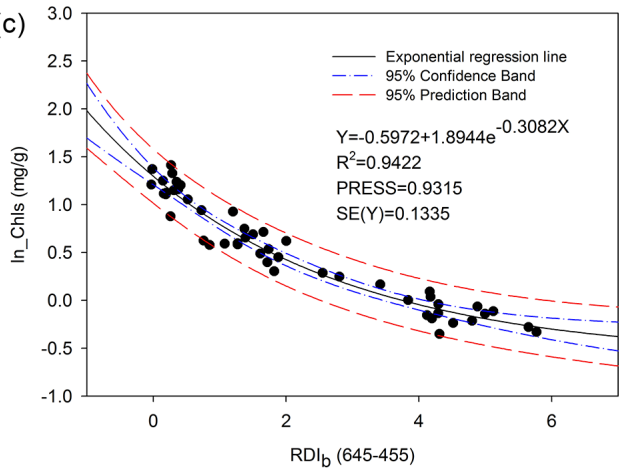

(e)

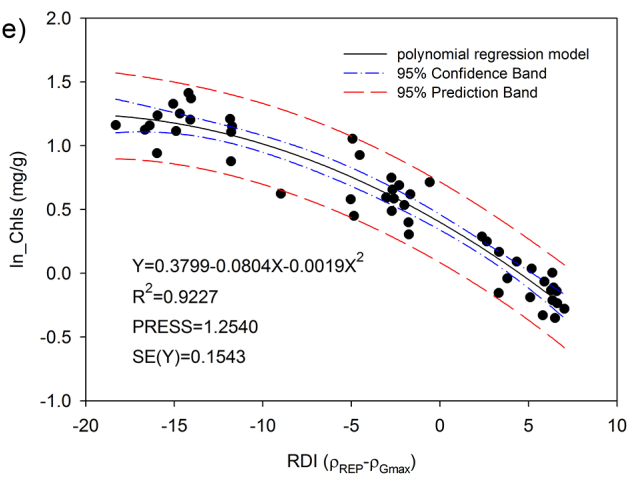

(b)

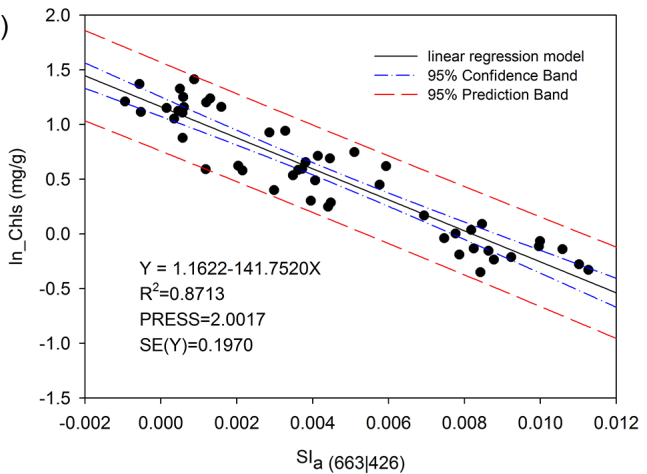

(d)

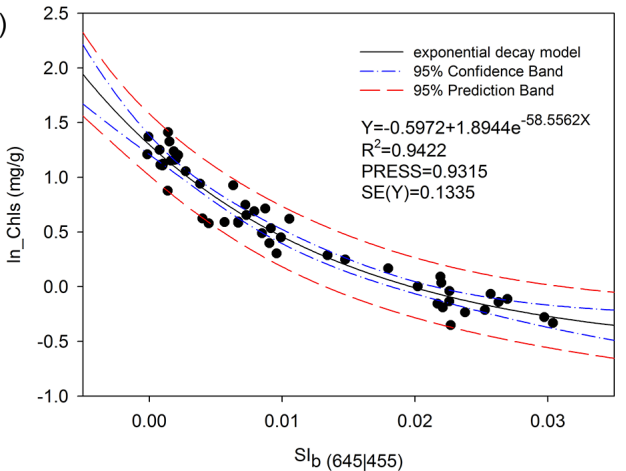

(f)

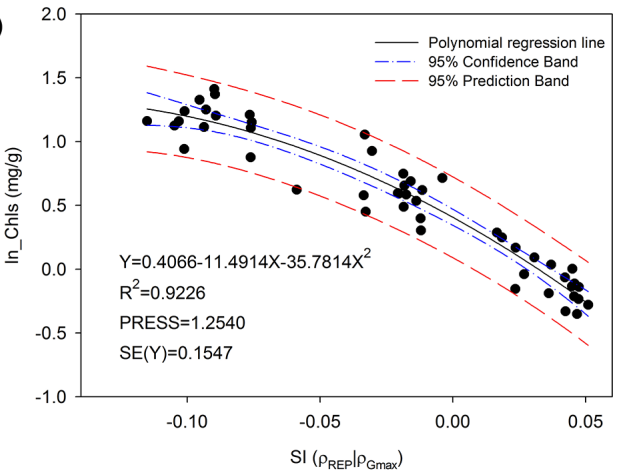

Figure 5. RDI- and SI-based empirical models for the estimation of foliar total chlorophyll concentration.

cients of first- and second-order variables are negative, indicating a higher value of foliar Chls has a lower value of

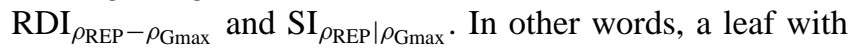
high chlorophyll concentration will have the reflectance at the red edge position far greater than the reflectance at the green peak position.

Figure 6 shows six empirical models with adequacy assessments for the estimation of foliar chlorophyll concentration using the ratio index of spectral features. Those models are all negatively related to the lnChls. Figure 7 shows the behavior of normalized difference indices with respect to the changes of foliar total chlorophyll concentration. The predictors $\mathrm{NDI}_{a}$ and $\mathrm{NDI}_{b}$ are linearly related to $1 \mathrm{nChls}$ (Fig. 7a and $b$ ). These two indices display a negative relationship in the estimation of lnChls, with an $R^{2}$ value of 0.67 and 0.83 $(P<0.01)$.

\subsubsection{Validation of empirical reflectance-based Chls models}

The empirical reflectance-based Chls models developed using the training samples were validated using another data set by using samples which contain fresh and water-stressed leaves. The Chls prediction bias was presented with the indicators RMSE and MAE in response to the group of fresh and water-stressed samples, that is, RMSEf, RMSEw, MAEf, and MAEw. The prediction biases of both fresh and waterstressed groups were averaged to get the mean values of RMSEa and MAEa. Details of the model validation and per- 
Table 3. Prediction accuracy assessment of the developed Chls empirical models.

\begin{tabular}{|c|c|c|c|c|c|c|c|c|c|}
\hline \multirow[t]{2}{*}{ Predictor } & \multicolumn{3}{|c|}{ Model adequacy } & \multicolumn{6}{|c|}{ Model validation } \\
\hline & $R^{2}$ & PRESS & $\mathrm{SE}(Y)$ & RMSEf & RMSEw & RMSEa & MAEf & MAEw & MAEa \\
\hline $\mathrm{RI}_{\mathrm{RDI}_{b} / \rho_{\mathrm{REP}}}$ & 0.90 & 1.55 & 0.17 & 0.35 & 0.38 & 0.36 & 15.85 & 12.49 & 14.17 \\
\hline $\mathrm{SI}_{b}$ & 0.94 & 0.93 & 0.13 & 0.46 & 0.43 & 0.44 & 19.07 & 14.63 & 16.85 \\
\hline $\mathrm{RI}_{\mathrm{RDI}_{b} / \lambda_{\mathrm{REP}}}$ & 0.94 & 0.93 & 0.13 & 0.46 & 0.42 & 0.44 & 19.33 & 14.47 & 16.90 \\
\hline $\mathrm{RDI}_{b}$ & 0.94 & 0.93 & 0.13 & 0.44 & 0.49 & 0.46 & 17.11 & 18.03 & 17.57 \\
\hline $\mathrm{NDI}_{\text {REPRDI } b}$ & 0.92 & 1.30 & 0.16 & 0.36 & 0.48 & 0.43 & 16.78 & 18.97 & 17.88 \\
\hline$\rho_{\mathrm{REP}}$ & 0.30 & 10.97 & 0.46 & 0.52 & 0.44 & 0.48 & 20.45 & 20.79 & 20.62 \\
\hline $\mathrm{NDI}_{b}$ & 0.84 & 2.49 & 0.22 & 0.40 & 0.55 & 0.48 & 21.11 & 24.36 & 22.74 \\
\hline $\mathrm{RI}_{b}$ & 0.83 & 2.70 & 0.23 & 0.39 & 0.54 & 0.47 & 21.49 & 24.01 & 22.75 \\
\hline $\mathrm{NDI}_{a}$ & 0.68 & 5.08 & 0.31 & 0.73 & 0.67 & 0.70 & 32.83 & 31.12 & 31.98 \\
\hline $\mathrm{RI}_{a}$ & 0.66 & 5.36 & 0.32 & 0.64 & 0.70 & 0.67 & 32.05 & 33.05 & 32.55 \\
\hline $\mathrm{SI}_{a}$ & 0.87 & 2.00 & 0.20 & 0.85 & 0.54 & 0.71 & 50.56 & 20.47 & 35.51 \\
\hline $\mathrm{RDI}_{a}$ & 0.74 & 9.98 & 0.44 & 0.85 & 0.54 & 0.71 & 50.56 & 20.47 & 35.51 \\
\hline $\mathrm{RI}_{\mathrm{SPAD}}$ & 0.79 & 3.41 & 0.25 & 0.79 & 0.49 & 0.66 & 48.04 & 36.20 & 42.12 \\
\hline $\mathrm{RDI}_{\rho_{\mathrm{REP}}-\rho_{\mathrm{Gmax}}}$ & 0.92 & 1.25 & 0.15 & 1.20 & 0.78 & 1.01 & 55.63 & 39.73 & 47.68 \\
\hline $\mathrm{SI}_{\rho_{\mathrm{REP}} \mid \rho_{\mathrm{Gmax}}}$ & 0.92 & 1.25 & 0.25 & 1.15 & 0.78 & 0.98 & 54.55 & 39.34 & 49.95 \\
\hline$\lambda_{\mathrm{REP}}$ & 0.90 & 1.59 & 0.18 & 1.18 & 0.64 & 0.95 & 56.05 & 48.43 & 52.24 \\
\hline $\mathrm{RI}_{\rho_{\mathrm{Gmax}} / \rho_{\mathrm{REP}}}$ & 0.93 & 1.06 & 0.14 & 0.40 & 1.17 & 0.88 & 16.33 & 89.52 & 52.93 \\
\hline$\rho_{645}$ & 0.77 & 3.57 & 0.26 & 0.98 & 0.63 & 0.82 & 60.38 & 46.41 & 53.39 \\
\hline $\mathrm{NDI}_{\text {REPGmax }}$ & 0.93 & 1.08 & 0.14 & 0.40 & 1.19 & 0.89 & 16.49 & 90.71 & 53.60 \\
\hline$\rho_{426}$ & 0.19 & 12.63 & 0.50 & 0.84 & 0.72 & 0.78 & 54.73 & 54.99 & 54.86 \\
\hline$\rho_{663}$ & 0.55 & 6.99 & 0.37 & 1.12 & 0.60 & 0.90 & 70.54 & 43.91 & 57.23 \\
\hline$\rho_{455}$ & 0.27 & 11.29 & 0.47 & 1.02 & 0.85 & 0.94 & 66.31 & 64.24 & 65.28 \\
\hline$\rho_{\mathrm{Gmax}}$ & 0.92 & 1.19 & 0.15 & 0.78 & 1.94 & 1.48 & 44.61 & 147.80 & 96.20 \\
\hline$\lambda_{\mathrm{Gmax}}$ & 0.10 & 14.09 & 0.52 & 0.90 & $>1000$ & $>1000$ & 57.00 & $>1000$ & $>1000$ \\
\hline
\end{tabular}

cent variances explained are listed in Table 3 . Among the 24 models, there are 11 models whose $R^{2}$ is greater than 0.90 $(P<0.01)$, PRESS less than 1.60, and $\operatorname{SE}(Y)$ less than 0.25 . Though those models have high $R^{2}$ values, the predicted Chls accuracy for the validation data set varies significantly. Some of the models have a big difference in prediction power for fresh leaves and water-stressed leaves samples. These results indicate that $\mathrm{RI}_{\rho \mathrm{Gmax} / \rho \mathrm{REP}}$ and $\mathrm{NDI}_{\mathrm{REPGmax}}$ models are only recommended for the Chls estimation of fresh leaves, while they failed to capture the changes caused by the water stress effect on spectral features variations.

Five models among those 24 models could be applied to estimate the foliar Chls of tree leaves because their predictor is able to capture accurately the Chls variation due to the changes of water content in leaves. The relatively high performance models have MAE ranges between 15-20 and 12-19\% for fresh leaves and water-stressed leaves, and have average MAEs between 14 and $18 \%$. The best validation among those reflectance-based Chls models was observed for the model with the predictor $\mathrm{RI}_{\mathrm{RDIb} / \rho \mathrm{REP}}$. Accordingly, we inferred that the reflectance variables $\rho_{645}, \rho_{455}$, and $\rho_{\text {REP }}$ are able to capture the key spectral features of foliar chlorophyll status and hence are effective predictors of foliar Chls.

In addition, the models with only one reflectance feature of the prototype variables, i.e., $\rho_{663}, \rho_{425}, \rho_{645}$, or $\rho_{455}$, will not be able to successfully predict foliar Chls. Finally, we found a conflict of agreement between model adequacy and validation for the models with the predictor $\lambda_{\text {REP }}$ and $\rho_{\text {REP }}$. Though $\lambda_{\text {REP }}$ is fitted very well with high adequacy $R^{2}=$ $0.90(P<0.01)$, its model is validated with MAEa $=52 \%$ and $\mathrm{RMSEa}=0.95 \mathrm{mg} \mathrm{g}^{-1}$; while $\rho_{\text {REP }}$ is not fitted very well, its $R^{2}=0.30$ is still significant at the 0.05 probability, and this model is validated with MAEa $=20 \%$ and RMSE $=0.48 \mathrm{mg} \mathrm{g}^{-1}$. The reflectance at green peak wavelength $\left(\rho_{\mathrm{Gmax}}\right)$ could be partially useful in the Chls prediction of fresh leaves.

Oki (2010) showed that ratio of reflectivity is able to give a good estimation of chlorophyll $a$ in lake water. Our results demonstrated that leaf chlorophyll concentration in cases of various water contents (fresh and/or water stressed) could be accurately predicted using spectral ratio indices such as RI (ratio index), SI (slope index), and NDI (normalized difference index) due to those indices effectively integrating the spectral features of chlorophyll $b$ and additionally the red edge characteristics. The model adequacy and the prediction accuracy validation of the empirical models have the same agreement. This leads to the answers of the hypotheses $\mathrm{HO1}$ and H02. First, the reflectance of ChlsPn is linearly and negatively related to foliar Chls, while the reflectance of red edge and green peak is linearly and positively related to foliar Chls. Second, the ChlsPn, red edge, and green peak cannot achieve an acceptable accuracy in the estimation of foliar 
(a)

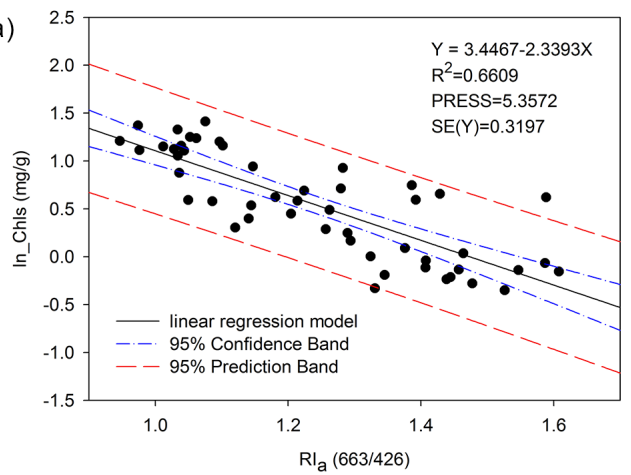

(c)

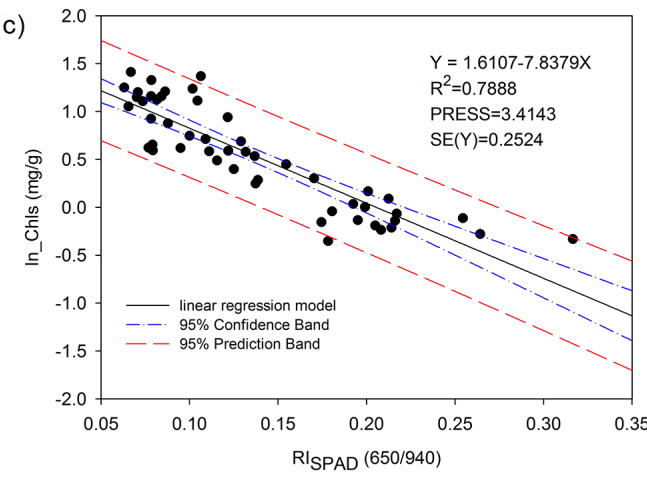

(e)

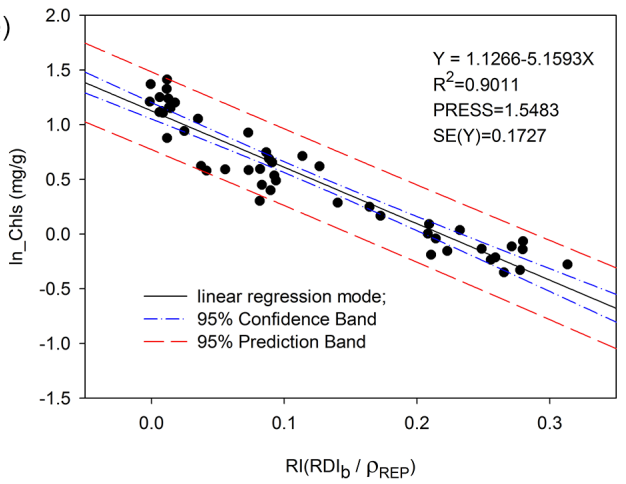

(b)

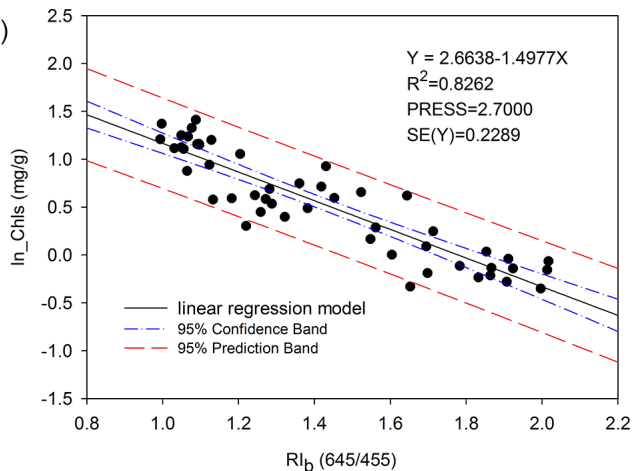

(d)

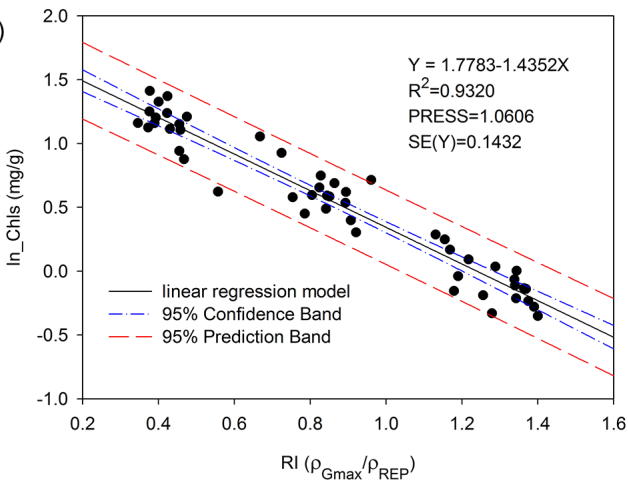

(f)

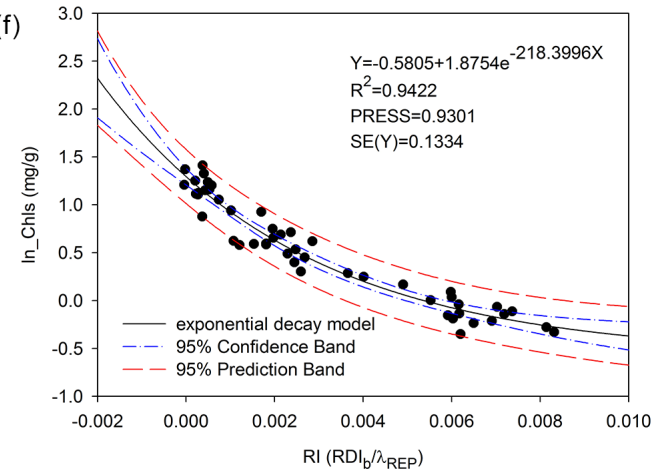

Figure 6. Ratio-index-based empirical models for foliar Chls concentration estimation.

Chls (for example MAE $<20 \%$ ) when they are used alone as predictors. Third, the ChlsPn variables can be integrated to produce a spectral difference index $\left(\mathrm{RDI}_{b}=\rho_{645}-\rho_{455}\right)$ or a spectral slope index $\mathrm{SI}_{b}=\left(\rho_{645}-\rho_{455}\right) /\left(\lambda_{645}-\lambda_{455}\right)$ to achieve an acceptable accuracy. Finally, ChlsPn and red edge characteristics can also be integrated as new spectral indices by the combination of reflectance difference and simple ratio.

Specifically, foliar Chls is significantly more related to the reflectance of $\rho_{645}$ and $\rho_{63}$ than $\rho_{455}$ and $\rho_{426}$. But the spectral difference index $\left(\mathrm{RDI}_{b}\right)$ and the slope index $\left(\mathrm{SI}_{b}\right)$ work much better than each of the four variables. Moreover, the prediction accuracy of the spectral difference index can be further improved by $17 \%$ if it is synergized with the reflectance at red edge position. That is an appropriate pre- dictor and can be derived by $\left(\rho_{645}-\rho_{455}\right) / \rho_{\mathrm{REP}}$, denoted as

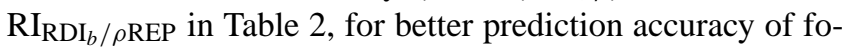
liar Chls in respect to various foliar water contents.

\subsubsection{A comparison with previously developed spectral indices of chlorophyll indicators}

Relationships between lnChls and the previous 18 spectral indices in Table 1 were developed using the training samples. The lnChls ( $y$ in Table 4) is mostly linearly and positively or negatively related to the indices, while an exponential decay relationship is observed between the lnChls and the indices TCI and $\mathrm{SR}_{775} \cdot R^{2}$ values for those models are mostly greater than 0.90 , only the model with $\mathrm{NDVI}_{680}$ 

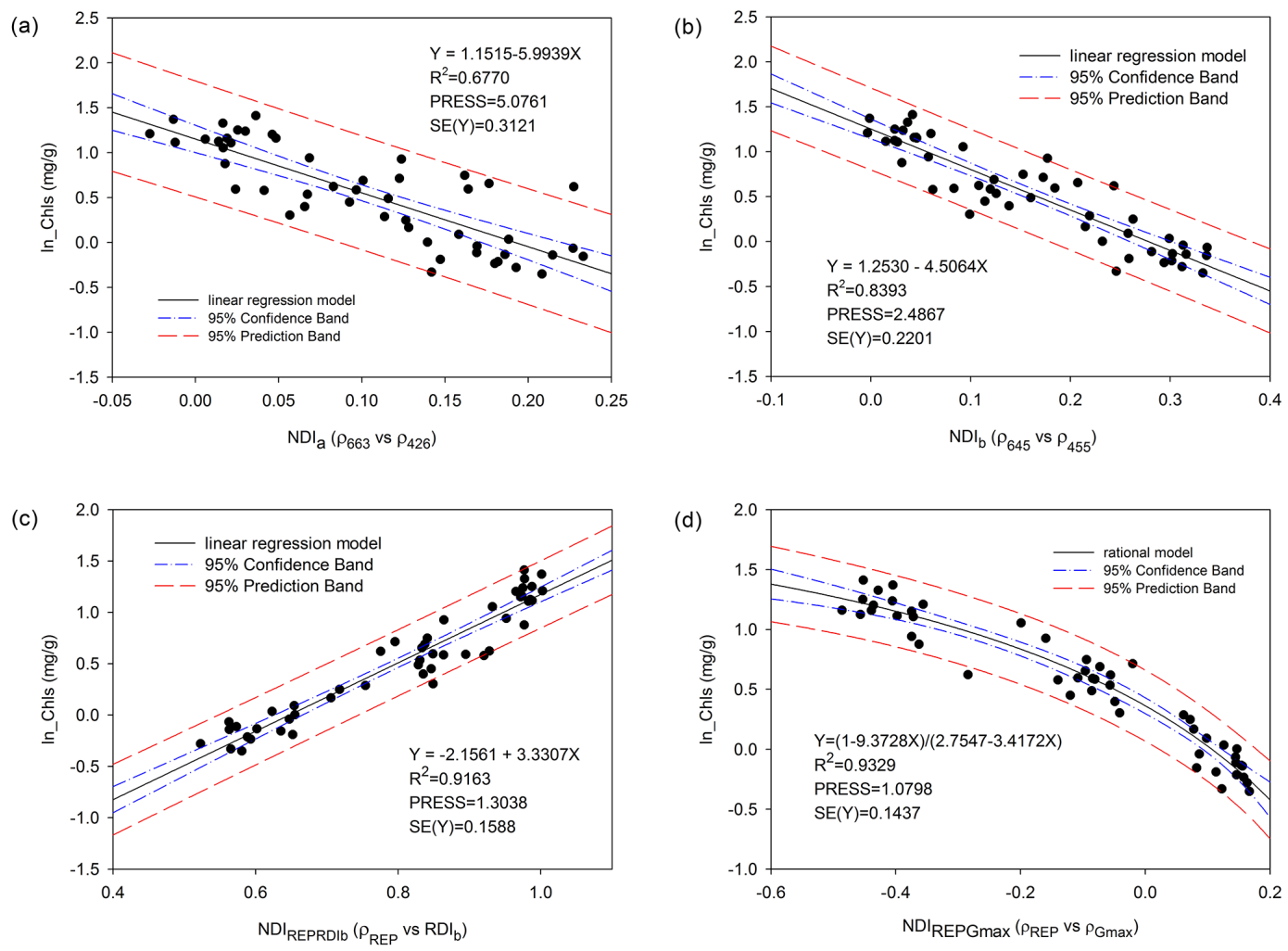

Figure 7. Normalized-difference-index-based empirical models for foliar Chls concentration estimation.

has an $R^{2}$ of 0.60 , showing a relatively poor model adequacy. Chls prediction accuracy of those models is between RMSE $0.87-4.57 \mathrm{mg} \mathrm{g}^{-1}$ or MAE $39-177 \%$ for both the fresh and water-stressed leaves (Table 5). The best accuracy was achieved by the indicator $\mathrm{CI}_{\text {red edge }}$ with an RMSE of 0.72 and $1.00 \mathrm{mg} \mathrm{g}^{-1}$ and an MAE of 27 and $53 \%$ for the fresh and water-stressed validation samples. The foliar Chls is linearly and positively related to $\mathrm{CI}_{\text {red edge }}$, as shown in Gitelson et al. (2009).

Although Ollinger (2011) suggested that the near-infrared region is the most important to vegetation remote sensing, a spectral index that combines the reflectance of nearinfrared and red edge wavelengths was not able to achieve the same accuracy level of the predictor $\mathrm{RI}_{\mathrm{RDI}} / \lambda_{\mathrm{REP}}$. Specifically, taking the average of the prediction accuracy of both fresh and water-stressed samples, the indicator $\mathrm{CI}_{\text {red edge }}$ could achieve an accuracy of RMSE $=0.87 \mathrm{mg} \mathrm{g}^{-1}$ and $\mathrm{MAE}=39 \%$. That is almost 2.5 times the average accuracy $\left(\mathrm{RMSE}=0.36 \mathrm{mg} \mathrm{g}^{-1}\right.$ and $\left.\mathrm{MAE}=14 \%\right)$ indicated by

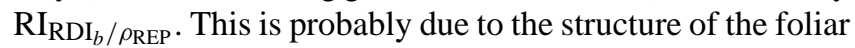
mesophyll which has changed when foliar water deficit happened. For example, Wuyts (2012) found that leaf thickness is conserved in response to water deficit under both high and low cumulative light regimes while mesophyll cells change in volume and shape. The change of the near-infrared reflectance is more complicated. Additional studies might be needed to explain the behavior of infrared reflectance in the future.

\subsection{Evaluation of the absorptance-based Chls model (the SPAD-502 method)}

\subsubsection{Nonlinearity relationship between In_transformed chlorophyll and SPAD readings}

SPAD readings and total chlorophyll concentration relationship was explored from an independent experiment of 45 fresh leaf samples of Cinnamomum camphora. A threeparameter rational function, $Y=(1+a X) /(b+c X)$ was most appropriate for presenting the relationship of SPAD reading $(X)$ and the lnChls $(Y)$ based on the ANOVA $F$ test of the fitted model and the $t$ test of the model's parameters. Fig. 8 showed that SPAD readings are nonlinearly dependent on the natural-log-transformed Chls. Specifically, the coefficients a, $\mathrm{b}$, and $\mathrm{c}$ of this fitted model were further $t$ tested to be significant at the 0.01 level. In total, 95.77 percent of the variance of lnChls could be explained by the SPAD chlorophyll rational model. Compared with the measured value determined by the acetone method, the fitted rational model has an average accuracy of $0.22 \mathrm{mg} \mathrm{g}^{-1}$ RMSE and $15 \%$ MAE that differ from the measured chlorophyll content for the training data set. 
Table 4. Narrow-band-based spectral indices developed as chlorophyll indicators.

\begin{tabular}{|c|c|c|c|c|}
\hline Indicator & Chls estimation models ( $y$ is $\operatorname{lnChls)}$ & $R^{2}$ & PRESS & $\operatorname{SE}(Y)$ \\
\hline Vog1 & $y=-4.0302+3.4801 \operatorname{Vog} 1$ & 0.94 & 0.95 & 0.13 \\
\hline Vog2 & $y=-0.4049-19.4238 \operatorname{Vog} 2$ & 0.94 & 0.95 & 0.13 \\
\hline $\operatorname{Vog} 3$ & $y=-0.3766-17.3277 \operatorname{Vog} 3$ & 0.94 & 0.94 & 0.13 \\
\hline $\mathrm{NDVI}_{705}$ & $y=-0.8710+3.6844 \mathrm{NDVI}_{705}$ & 0.92 & 1.21 & 0.15 \\
\hline $\mathrm{NDVI}_{700}$ & $y=-1.0487+3.1896 \mathrm{NDVI}_{700}$ & 0.91 & 1.46 & 0.17 \\
\hline $\mathrm{SR}_{700}$ & $y=-0.8609+0.4175 \mathrm{SR}_{700}$ & 0.94 & 1.00 & 0.14 \\
\hline wSR & $y=-0.3406+5.5226 \mathrm{wSR}$ & 0.91 & 1.47 & 0.17 \\
\hline $\mathrm{NDVI}_{680}$ & $y=-5.5313+7.5436 \mathrm{NDVI}_{680}$ & 0.60 & 6.29 & 0.35 \\
\hline MCARI & $y=1.3432-0.0192 \mathrm{MCARI}$ & 0.82 & 2.86 & 0.24 \\
\hline $\mathrm{mSR}$ & $y=-0.9494+0.5288 \mathrm{mSR}$ & 0.94 & 0.91 & 0.13 \\
\hline mNDVI & $y=-0.8980+3.2961 \mathrm{mNDVI}$ & 0.92 & 1.31 & 0.16 \\
\hline MTCI & $y=-0.4718+0.9146 \mathrm{MTCI}$ & 0.94 & 1.01 & 0.14 \\
\hline $\mathrm{rSR}_{705}$ & $y=-0.4432+0.6887 \mathrm{rSR}_{705}$ & 0.94 & 0.91 & 0.13 \\
\hline TCI & $y=3.7126 \cdot \exp (-0.0743 \mathrm{TCI})$ & 0.88 & 1.94 & 0.19 \\
\hline $\mathrm{SR}_{775}$ & $y=22.5416 \cdot \exp \left(-8.1018 \mathrm{SR}_{775}\right)$ & 0.90 & 1.56 & 0.17 \\
\hline $\mathrm{NDVI}_{712}$ & $y=-0.6772+4.7009 \mathrm{NDVI}_{712}$ & 0.93 & 1.15 & 0.15 \\
\hline TGI & $y=1.7411-0.0011 \mathrm{TGI}$ & 0.93 & 1.11 & 0.15 \\
\hline $\mathrm{SR}_{760}$ & $y=-0.3563+3.4783 \cdot \exp \left(-6.6687 \mathrm{SR}_{760}\right)$ & 0.91 & 1.50 & 0.17 \\
\hline $\mathrm{SR}_{420}$ & $y=1.8611-0.4905 \mathrm{SR}_{420}$ & 0.66 & 5.24 & 0.32 \\
\hline $\mathrm{CI}_{\text {red edge }}$ & $y=-0.5205+0.4737 \mathrm{CI}_{\text {red edge }}$ & 0.93 & 1.05 & 0.14 \\
\hline
\end{tabular}

\subsubsection{Limitation of the SPAD reading-based rational model}

According to the experiment, we found that the SPAD reading increases positively relative to the chlorophyll concentration in fresh leaves. The SPAD reading remained at a high value even when leaves were under serious water stress, that is, the SPAD reading rises to a high level even the chlorophyll content is decreasing. It revealed that the previously mentioned nonlinear rational model is not suitable for those wilting leaves. Figure 9 showed a deficiency of the SPAD reading-based model in the estimation of foliar chlorophyll content. The Chls estimates of fresh leaves (presented as solid black circles) are mostly located under the real Chls line (i.e., under estimation), and the Chls estimates of waterstressed leaves (presented as open circles) are mainly located above the real Chls line (i.e., overestimation). The biases RMSE and MAE of Chls estimation were evaluated to be $0.29 \mathrm{mg} \mathrm{g}^{-1}$ and $16 \%$ for the fresh leaves sample and $0.92 \mathrm{mg} \mathrm{g}^{-1}$ and $60 \%$ for the water-stressed leaf sample. The fresh leaves sample has biases very close to the values (RMSE $0.22 \mathrm{mg} \mathrm{g}^{-1}$ and MAE $15 \%$ ) of the original modeling data set, but the water-stressed leaves sample has biases almost 4 times that of the original modeling data set. This finding indicates that the SPAD rational model can achieve a very good and acceptable Chls estimates in case of fresh leaves, while unfortunately it fails if the leaves are under water-stressed conditions. This result leads to the acceptance of the null hypothesis $\mathrm{H} 03$ and concludes that the determination of Chls using the chlorophyll meter (absorptance-based

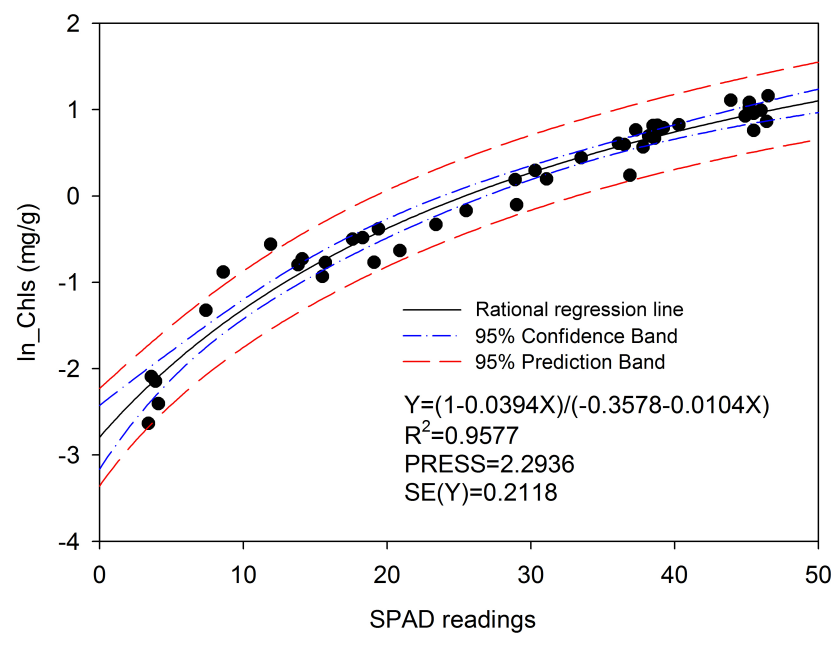

Figure 8. Rational regression model for foliar chlorophyll contents estimation. Number of data points is 45 . In the rational model, the independent variable SPAD readings could be used to explain $95.77 \%\left(R^{2}\right)$ variation of the dependent variable, lnChls, the natural-logarithm-transformed foliar chlorophyll content.

model) has a significant bias or uncertainty due to its failure in responding to the influence of water stress.

\section{Conclusions}

Typical vegetation reflectance is significantly related to foliar biochemistry and biophysical characteristics. A stronger negative relationship exists between the 
Table 5. Foliar Chls prediction accuracy of the previously developed spectral indices.

\begin{tabular}{|c|c|c|c|c|c|c|}
\hline \multirow{2}{*}{$\begin{array}{l}\text { Error index } \\
\text { Chls indicator }\end{array}$} & \multicolumn{3}{|c|}{$\operatorname{RMSE}\left(\mathrm{mgg}^{-1}\right)$} & \multicolumn{3}{|c|}{$\operatorname{MAE}(\%)$} \\
\hline & Fresh sample & Wilted sample & All & Fresh sample & Wilted sample & All \\
\hline Vog1 & 1.91 & 0.33 & 1.37 & 78.35 & 13.96 & 46.15 \\
\hline $\operatorname{Vog} 2$ & 3.01 & 0.41 & 2.15 & 111.33 & 27.99 & 69.66 \\
\hline $\operatorname{Vog} 3$ & 3.27 & 0.39 & 2.33 & 115.85 & 25.78 & 70.81 \\
\hline $\mathrm{NDVI}_{705}$ & 1.43 & 0.54 & 1.08 & 78.32 & 39.56 & 58.94 \\
\hline $\mathrm{NDVI}_{700}$ & 1.36 & 0.86 & 1.14 & 82.51 & 63.74 & 73.12 \\
\hline $\mathrm{SR}_{700}$ & 4.28 & 0.48 & 3.04 & 155.11 & 34.37 & 94.74 \\
\hline wSR & 3.65 & 2.49 & 3.12 & 93.48 & 170.68 & 132.08 \\
\hline $\mathrm{NDVI}_{680}$ & 1.27 & 0.47 & 0.95 & 78.15 & 32.27 & 55.21 \\
\hline MCARI & 1.06 & 1.55 & 1.33 & 71.17 & 119.34 & 95.26 \\
\hline $\mathrm{mSR}$ & 6.44 & 0.41 & 4.57 & 173.85 & 28.68 & 101.26 \\
\hline mNDVI & 1.46 & 0.57 & 1.11 & 78.08 & 42.21 & 60.14 \\
\hline MTCI & 2.80 & 0.34 & 1.99 & 95.57 & 22.05 & 58.81 \\
\hline $\mathrm{rSR}_{705}$ & 3.62 & 0.54 & 2.59 & 129.23 & 39.78 & 84.50 \\
\hline TCI & 2.67 & 3.67 & 3.21 & 85.89 & 268.02 & 176.95 \\
\hline $\mathrm{SR}_{775}$ & 5.98 & 0.38 & 4.24 & 171.87 & 26.43 & 99.15 \\
\hline $\mathrm{NDVI}_{712}$ & 1.49 & 0.54 & 1.12 & 72.86 & 40.55 & 56.71 \\
\hline TGI & 0.57 & 2.33 & 1.70 & 30.13 & 178.95 & 104.54 \\
\hline $\mathrm{SR}_{760}$ & 1.93 & 0.54 & 1.41 & 102.96 & 38.92 & 70.94 \\
\hline $\mathrm{SR}_{420}$ & 0.99 & 0.83 & 0.92 & 63.28 & 61.48 & 62.38 \\
\hline $\mathrm{CI}_{\text {broad band }}$ & 0.71 & 1.00 & 0.87 & 27.10 & 51.86 & 39.48 \\
\hline
\end{tabular}

chlorophyll concentration and the visible reflectance while the relationship of the chlorophyll concentration and the infrared reflectance is positive. As water stress occurred, the reflectance over the visible and infrared area will increase. The estimation of chlorophyll concentration using only the remotely sensed reflectance will be seriously affected by the reflectance changes caused by a departure of water content from the non-water-stressed conditions. The significant uncertainty for the estimation of chlorophyll concentration is caused by the reflectance changes induced by variations of the foliar water content. Red edge characteristics, such as position $\left(\lambda_{\mathrm{REP}}\right)$ and reflectance $\left(\rho_{\mathrm{REP}}\right)$, are also sensitive to water stress. Each of them, as a predictor of foliar Chls, has a significant positive linear relationship with foliar chlorophyll concentration. This is similar to the results of Matson et al. (1994) and Belanger et al. (1995).

The ChlsPn variables, such as the reflectance at the wavelengths $663,645,455$, and $426 \mathrm{~nm}$, are in particular directly related to the light absorption by chlorophyll $a$ and chlorophyll $b$ and therefore can characterize the foliar chlorophyll concentration. The relationship between Chls and each of the variables $\rho_{426}, \rho_{455}, \rho_{645}$, and $\rho_{663}$ is statistically significant, but is still not good enough to be used alone for Chls estimation. The best adequacy $\left(R^{2}\right)$ of the four reflectancebased ChlsPn models using one of the ChlsPn variables as the predictor is 0.77 , meanwhile the best average accuracy achieved is $\mathrm{MAE}=54 \%$ and $\mathrm{RMSE}=0.78 \mathrm{mg} \mathrm{g}^{-1}$ for both fresh and water-stressed leaves. Spectral indices derived from ChlsPn variables by the methods of normalized

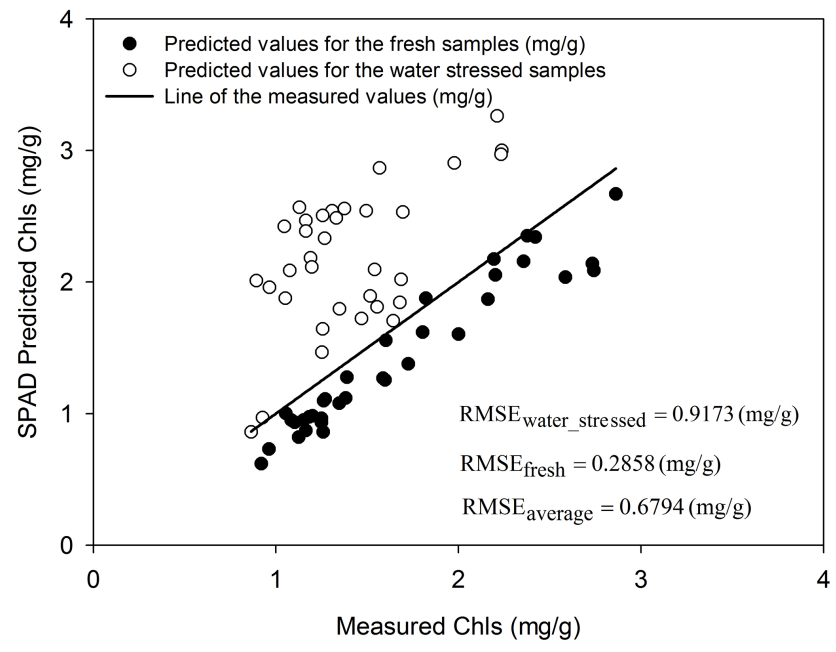

Figure 9. Evaluation of the prediction accuracy of the SPAD chlorophyll regression model. Number of data points is 70 . For testing fresh samples, the estimation error is $0.2858 \mathrm{mg} \mathrm{g}^{-1}$; for testing samples which are water stressed, the error is $0.9173 \mathrm{mg} \mathrm{g}^{-1}$. Average error is $0.6794 \mathrm{mg} \mathrm{g}^{-1}$ for all of the testing data points.

difference, simple difference, slope transformation, and simple ratio can effectively improve the estimation accuracy of the reflectance-based Chls spectral index models. The better accuracy is the model using the slope index $\mathrm{SI}_{b}$ with $\mathrm{MAE}=17 \%$ and $\mathrm{RMSE}=0.44 \mathrm{mg} \mathrm{g}^{-1}$ or the difference index $\mathrm{RDI}_{b}$ with $\mathrm{MAE}=18 \%$ and $\mathrm{RMSE}=0.46 \mathrm{mg} \mathrm{g}^{-1}$. By integrating the reflectance at the red edge position, the 
difference-based simple ratio index $\left(\rho_{645}-\rho_{455}\right) / \rho_{\text {REP }}$ can achieve the best accuracy of the Chls of fresh and waterstressed leaves. The MAE and RMSE are further decreased down to $14 \%$ and $0.36 \mathrm{mg} \mathrm{g}^{-1}$, respectively.

Plant growth and productivity are mostly affected by water shortage. This stress condition induces plant cell dehydration and then causes the decreased chlorophyll in older leaves. Since the influence of water stress on foliar spectral reflectance could be effectively reduced by the reflectance at the red edge and the wavelengths of 645 and $455 \mathrm{~nm}$, we recommend the following three spectral indices as an effective chlorophyll indicator (ECI) for dealing with the potential influence of foliar water deficit for applications. The first predictor is the difference-based red edge reflectance ratio index ECI $1=\left(\rho_{645}-\rho_{455}\right) / \rho_{\text {REP }}$, then the slope index ECI2 $=$ $\left(\rho_{645}-\rho_{455}\right) /\left(\lambda_{645}-\lambda_{455}\right)$, and finally the difference-based red edge position ratio index ECI3 $=\left(\rho_{645}-\rho_{455}\right) / \lambda_{\text {REP }}$. ECI1 is negatively and linearly related to chlorophyll concentration, while ECI2 and ECI3 are exponential and negatively related to the natural-log-transformed foliar chlorophyll concentration. A temporal and spatial estimation of the chlorophyll content for the terrestrial ecosystems could be retrieved more feasibly and accurately using these effective chlorophyll indicators.

Acknowledgements. The authors would like to acknowledge the support provided by project NSC 102-2119-M-415-001 funded by the National Science Council, Taiwan.

Edited by: F. Chai

\section{References}

Arnon, D. I.: Copper enzymes in isolated chloroplasts. Polyphenoloxidase in Beta vulgaris, Plant Physiol., 24, 1-15, 1949.

Blackburn, G. A.: Quantifying chlorophyll and caroteniods at leaf and canopy scales: an evaluation of some hyperspectral approaches, Remote Sens. Environ., 66, 273-285, 1998.

Blackburn, G. A.: Hyperspectral remote sensing of plant pigments, J. Exp. Bot., 58, 855-867, 2007.

Blackburn, G. A. and Ferwerda, J. G.: Retrieval of chlorophyll concentration from leaf reflectance spectra using wavelet analysis, Remote Sens. Environ., 112, 1614-1632, 2008.

Blackmer, T. M. and Schepers, J. S.: Use of a chlorophyll meter to monitor nitrogen status and schedule fertigation for corn, J. Prod. Agric., 8, 56-60, 1995.

Belanger, M. J., Miller, J. R., and Boyer, M. G.: Comparative relationships between some red edge parameters and seasonal leaf chlorophyll concentrations, Can. J. Remote Sens., 21, 16-21, 1995.

Boegh, E., Houborg, R., Bienkowski, J., Braban, C. F., Dalgaard, T., van Dijk, N., Dragosits, U., Holmes, E., Magliulo, V., Schelde, K., Di Tommasi, P., Vitale, L., Theobald, M. R., Cellier, P., and Sutton, M. A.: Remote sensing of LAI, chlorophyll and leaf nitrogen pools of crop- and grasslands in five European landscapes,
Biogeosciences, 10, 6279-6307, doi:10.5194/bg-10-6279-2013, 2013.

Carter, G. A.: Primary and secondary effects of water content on the spectral reflectance of leaves, Am. J. Bot., 78, 916-924, 1991.

Carter, G. A.: Responses of leaf spectral reflectance to plant stress, Am. J. Bot., 80, 239-243, 1993.

Carter, G. A.: Ratios of leaf reflectances in narrow wavebands as indicators of plant stress, Int. J. Remote Sens., 15, 697-703, 1994.

Carter, G. A. and Knapp, A. K.: Leaf optical properties in higher plants, Linking spectral characteristics to stress and chlorophyll concentration, Am. J. Bot., 88, 677-684, 2001.

Cate, T. M. and Perkins, T. D.: Chlorophyll content monitoring in sugar maple (Acer saccharum), Tree Physiol., 23, 1077-1079, 2003.

Ceccato, P., Flasse, S., Tarantola, S., Jacquemoud, S., and Gregoire, J. M.: Detecting vegetation leaf water content using reflectance in the optical domain, Remote Sens. Environ., 77, 22-33, 2001.

Cheng, T., Rivard, B., and Sanchez-Azofeifa, A.: Spectroscopic determination of leaf water content using continuous wavelet analysis, Remote Sens. Environ., 115, 659-670, 2011.

Curran, P. J., Dungan, J. L., and Gholz, H. L.: Exploring the relationship between reflectance red edge and chlorophyll content in slash pine, Tree Physiol., 7, 33-48, 1990.

Curran, P. J., Dungan, J. L., Macler, B. A., and Plummer, S. E.: The effect of a red leaf pigment on the relationship between red edge and chlorophyll concentration, Remote Sens. Environ., 35, 69-76, 1991.

Curtiss, B. and Goetz, A. F. H.: Field Spectrometry: Techniques and Instrumentation, Proceedings of ISSSR 1994, 10-15 July, San Diego, California, 1, 195-203, 1994.

Dash, J. and Curran, P .J.: The MERIS terrestrial chlorophyll index, Int. J. Remote Sens., 25, 5403-5413, 2004.

Datt, B.: Remote sensing of chlorophyll $a$, chlorophyll $b$, chlorophyll $a+b$, and total carotenoid content in eucalyptus leaves, Remote Sens. Environ., 66, 111-121, 1998.

Daughtry, C. S. T., Walthall, C. L., Kim, M. S., de Colstoun, E. B., and McMurtrey III, J. E.: Estimating corn leaf chlorophyll concentration from leaf and canopy reflectance, Remote Sens. Environ., 74, 229-239, 2000.

Dawson, T. P., Curran, J. P., and Plummer, S. E.: LIBERTY - Modeling the effects of leaf biochemical concentration on reflectance spectra, Remote Sens. Environ., 65, 50-60, 1998.

Desotgiu, R., Pollastrini, M., Cascio, C., Gerosa, G., Marzuoli, R., and Bussotti, F.: Chlorophyll a fluorescence analysis along a vertical gradient of the crown in a poplar (Oxford clone) subjected to ozone and water stress, Tree Physiol., 32, 976-986, 2012.

Elvidge, C. D., and Chen, Z.: Comparison of Broad-band and Narrow-band Red and Near-Infrared Vegetation Indices, Remote Sens. Environ., 54, 38-48, 1995.

Emerson, R. and Lewis, C. M.: The dependence of the quantum yield of Chlorella photosynthesis on wavelength of light, Am. J. Bot., 30, 165-178, 1943.

Estep, L. and Carter, G. A.: Derivative Analysis of AVIRIS Data for Crop Stress Detection, Photogram. Eng. Rem. S., 71, 1417-1421, 2005.

Féret, J. B., Francois, C., Gitelson, A., Asner, G. P., Barry, K. M., Panigada, C., Richardson, A. D., and Jacquemoud, S.: Optimizing spectral indices and chemometric analysis of leaf chemical 
properties using radiative transfer modeling, Remote Sens. Environ., 115, 2742-2750, 2011.

Filella, I. and Peñuelas, J.: The red edge position and shape as indicative plant chlorophyll content, biomass and hydric states, Int. J. Remote Sens., 15, 1459-1470, 1994.

Gausman, H. W. and Allen, W. A.: Optical parameters of leaves of 30 plant species, Plant Physiol., 52, 57-62, 1973.

Gausman, H. W., Escobar, D. E., and Rodriguez, R. R.: Reflectance measurements of cotton leaf senescence altered by mepiquat chloride, USDA/Agricultural Research Service, Remote Sensing Research Unit, Weslaco, Texas, 1982.

Ghorbanli, M., Gafarabad, M., Amirkian, T., and Allahverdi Mamaghani, B.: Investigation of proline, total protein, chlorophyll, ascorbate and dehydroascorbate changes under drought stress in Akria and Mobil tomato cultivars, Iran. J. Plant Physiol., 3, 651658,2013

Gitelson, A. A. and Merzlyak, M. N.: Spectral reflectance changes associated with autumn senescence of Aesculus hippocastanum L. and Acer platanoides L. leaves. Spectral features and relation to chlorophyll estimation, J. Plant Physiol., 143, 286-292, 1994a.

Gitelson, A. A. and Merzlyak, M. N.: Quantitative estimation of chlorophyll-a using reflectance spectra-experiments with autumn chestnut and maple leaves, J. Photochem. Photobiol., B, 22, 247252, 1994b.

Gitelson, A. A. and Merzlyak, M. N.: Signature analysis of leaf reflectance spectra: algorithm development for remote sensing of chlorophyll, J. Plant Physiol., 148, 494-500, 1996.

Gitelson, A. A., and Merzlyak, M. N.: Remote estimation of chlorophyll content in higher plant leaves, Int. J. Remote Sens., 18, 2691-2697, 1997.

Gitelson, A. A., Gritz, U., and Merzlyak, M. N.: Relationships between leaf chlorophyll content and spectral reflectance and algorithms for non-destructive chlorophyll assessment in higher plant leaves, J. Plant Physiol., 160, 271-282, 2003.

Gitelson, A. A., Keydan, G. P., and Merzlyak, M. N.: Three-band model for noninvasive estimation of chlorophyll, carotenoids, and anthocyanin contents in higher plant leaves, Geophys. Res. Lett, 33, L11402, doi:10.1029/2006GL026457, 2006.

Gitelson, A. A., Chivkunova, O. B., and Nerzlyak, M. N.: Nondestructive estimation of anthocyanins and chlorophylls in anthocyanic leaves, Am. J. Bot., 96, 1861-1868, 2009.

Gond, V., de Pury, D. G. G., Veroustraete, F., and Ceulemans, R.: Seasonal variations in leaf area index, leaf chlorophyll, and water content; scaling-up to estimate fAPAR and carbon balance in a multilayer, multispecies temperate forest, Tree Physiol., 19, 673679,1999

Haboudane, D., Tremblay, N., Miller, J. R., and Vigneault, P.: Remote estimation of crop chlorophyll content using spectral indices derived from hyperspectral data, IEEE Trans. Geosci. Remote Sens., 46, 423-437, 2008. Hatchell, D. C.: Analytical Spectral Devices. 4th edition, Technical Guide, ASD Inc, 1999.

Hawkins, T. S., Gardiner, E. S., and Comer, G. S.: Modeling the relationship between extractable chlorophyll and SPAD-502 readings for endangered plant species research, J. Nat. Conserv., 17, 125-129, 2009.

Hopkins, W. G. and Hüner, N. P. A.: Introduction to Plant Physiology, 3rd ed, John Wiley \& Sons, NJ, 2004.

Horler, D. N. H., Dockray, M., and Barber, J.: The red edge of plant leaf reflectance, Int. J. Remote Sens., 4, 273-288, 1983.
Hunt, E. R., Daughtry, C. S. T., Eitel, J. U. H., and Long, D. S.: Remote sensing leaf chlorophyll content using a visible band index, Agron. J., 103, 1090-1099, 2011.

Hunt, E. R., Doraiswamy, P. C., McMurtrey, J. E., Daughtry, C. S. T., Perry, E. M., and Akhmedov, B.: A visible band index for remote sensing leaf chlorophyll content at the canopy scale, Int J. Appl. Earth. Obs., 103, 1090-1099, 2013.

Hunt, E. R. and Rock, B. N.: Detection of changes in leaf water content using near- and middle-infrared reflectances, Remote Sens. Environ., 30, 43-54, 1989.

Jongschaap, R. E. E. and Booij, R.: Spectral measurements at different spatial scales in potato: relating leaf, plant and canopy nitrogen status, Int. J. Appl. Earth Obs., 5, 204-218, 2004.

Kaoau, M. E., Hsissou, D., and Belhadri, A.: Water Deprivation Effect on Pigments and Proline Content, and Growth in Cultivated Wheat Varieties in Morocco, Afr. Crop Sci. J., 15, 139147, 2007.

Keenan, T., García, R., Friend, A. D., Zaehle, S., Gracia, C., and Sabate, S.: Improved understanding of drought controls on seasonal variation in Mediterranean forest canopy $\mathrm{CO}_{2}$ and water fluxes through combined in situ measurements and ecosystem modelling, Biogeosciences, 6, 1423-1444, doi:10.5194/bg6-1423-2009, 2009.

Kirnak, H., Kaya, C., Tas, I., and Higgs, D.: The influence of water deficit on vegetative growth, physiology, fruit yield and quality in eggplants, Bulg. J. Plant Physiol., 27, 34-46, 2001.

Knipling, E. B.: Physical and physiological basis for the reflectance of visible and near-infrared radiation from vegetation, Remote Sens. Environ., 1, 155-159, 1970.

Lavoir, A.-V., Staudt, M., Schnitzler, J. P., Landais, D., Massol, F., Rocheteau, A., Rodriguez, R., Zimmer, I., and Rambal, S.: Drought reduced monoterpene emissions from the evergreen Mediterranean oak Quercus ilex: results from a throughfall displacement experiment, Biogeosciences, 6, 1167-1180, doi:10.5194/bg-6-1167-2009, 2009.

Lin, C., Tsogt, K., and Chang, C. I.: An empirical model-based method for signal restoration of SWIR in ASD field spectroradiometry, Photogramm. Eng. Rem. S., 78, 119-127, 2012.

Ma, B. L., Morrison, M. J., and Voldeng, H. D.: Leaf greenness and photosynthetic rates in soybean, Crop Sci., 35, 1411-1414, 1995.

Matson, P., Johnson, L., Billow, C., Miller, J., and Pu, R.: Seasonal patterns and remote spectral estimation of canopy chemistry across the Oregon transect, Ecol. Appl., 4, 280-298, 1994.

Montagu, K. D. and Woo, K. C.: Recovery of tree photosynthetic capacity from seasonal drought in the wet-dry tropicsw: The role of phyllode and canopy processes in Acacia auriculiformis, Aust. J. plant Physiol., 26, 135-145, 1999.

Mutanga, O. and Skidmore, A. K.: Red edge shift and biochemical content in grass canopies, ISPRS J Photogramm. Rem. S., 62, 34-42, 2007.

Nave, L. E., Gough, C. M., Maurer, K. D., Bohrer, G., Hardiman, B. S., Le Moine, J., Munoz, A. B., Nadelhoffer, K. J., Sparks, J. P., Strahm, B. D., Vogel, C. S., and Curtis, P. S.: Disturbance and the resilience of coupled carbon and nitrogen cycling in a north temperate forest, J. Geophys. Res., 116, G04016, doi:10.1029/2011JG001758, 2011.

Nilsen, E. T. and Orcutt, D. M.: Physiology of plants under stress, Abiotic Factors, 2nd Edn. John Wiley \& Sons Inc., NY, 1996. 
Nobel, P. S.: Physicochemical and environmental plant physiology, 3rd ed, Academic Elsevier, Burlingtom, MA, 2005.

Novo, E., Gastil, M., and Melack, J.: An algorithm for chlorophyll using first difference transformations of AVIRIS reflectance spectra, Summaries of the Fifth Annual JPL Airborne Earth Science Workshop, NASA Jet Propulsion Laboratory publication 95-1, Pasadena, CA, 121-124, 1995.

Oki, K.: Why is the Ratio of Reflectivity Effective for Chlorophyll Estimation in the Lake Water?, Remote Sens., 2, 1722-1730, 2010.

Ollinger, S. V.: Sources of variability in canopy reflectance and the convergent properties of plants, New Phytol, 189, 375-394, 2011.

Pinar, A. and Curran, P. J.:, Grass chlorophyll and reflectance red edge, Int. J. Remote Sens., 17, 351-357, 1996.

Pirzad, A., Shakiba, M. R., Zehtab-Salmasi, S., Mohammadi, S. A., Darvishzadeh, R., and Samadi, A.: Effect of water stress on leaf relative water content, chlorophyll, praline and soluble carbohydrates in Matricaria chamomilla L., J. Med. Plants Res., 5, 24832488, 2011.

Pu, R., Ge, S., Kelly, N. M., and Gong, P.: Spectral absorption features as indicators of water status in coast live oak (Quercus agrifolia) leaves, Int. J. Remote Sens., 24, 1799-1810, 2003.

Rascher, U., Agati, G., Alonso, L., Cecchi, G., Champagne, S., Colombo, R., Damm, A., Daumard, F., de Miguel, E., Fernandez, G., Franch, B., Franke, J., Gerbig, C., Gioli, B., Gomeź, J. A., Goulas, Y., Guanter, L., Gutiérrez-de-la-Cámará, O., Hamdi, K., Hostert, P., Jimeneź, M., Kosvancova, M., Lognoli, D., Meroni, M., Miglietta, F., Moersch, A., Moreno, J., Moya, I., Neininger, B., Okujeni, A., Ounis, A., Palombi, L., Raimondi, V., Schickling, A., Sobrino, J. A., Stellmes, M., Toci, G., Toscano, P., Udelhoven, T., van der Linden, S., and Zaldei, A.: CEFLES2: the remote sensing component to quantify photosynthetic efficiency from the leaf to the region by measuring sun-induced fluorescence in the oxygen absorption bands, Biogeosciences, 6, 11811198, doi:10.5194/bg-6-1181-2009, 2009.

Read, J. J., Whaley, E. L., Tarpley, L., and Reddy, R.: Evaluation of a Hand-held Radiometer for Field Determination of Nitrogen Status in Cotton, in: Digital Imaging and Spectral Techniques: Applications to Precision Agriculture and Crop Physiology, edited by: Schepers J. and T. von Toai, ASA, Madison, Wis, 171-189, 2003.

Reddy, K. R. and Matcha, S. K.: Remote sensing algorithms for castor bean nitrogen and pigment assessment for fertility management, Ind. Crop. Prod., 32, 411-419, 2010.

Rossini, M., Cogliati, S., Meroni, M., Migliavacca, M., Galvagno, M., Busetto, L., Cremonese, E., Julitta, T., Siniscalco, C., Morra di Cella, U., and Colombo, R.: Remote sensing-based estimation of gross primary production in a subalpine grassland, Biogeosciences, 9, 2565-2584, doi:10.5194/bg-9-2565-2012, 2012.
Rowland, D., Blankenship, P., Puppala, N., Beasley, J., Burow, M., Gorbet, D., Jordan, D., Melouk, H., Simpson, C., and Bostick, J.: Variation in water-use efficiency of peanut varieties across peanut production regions, http://www.cropscience. org.au/icsc2004/poster/1/3/2/288_rowlanddl.htm (Last access: November 10, 2012), 2004.

Schelbert, S., Aubry, S., Burla, B., Agne, B., Kessler, F., Krupinska, K., and Hörtensteiner, S.: Pheophytin pheophorbide hydrolase (pheophytinase) is involved in chlorophyll breakdown during leaf senescence in Arabidopsis, Plant Cell, 21, 767-785, 2009.

Sims, D. A. and Gamon, J. A.: Relationships between leaf pigment content and spectral reflectance across a wide range of species, leaf structures and development stages, Remote Sens. Environ., 81, 337-354, 2002.

Takebe, M., Yoneyama, T., Inada, K., and Murakami, T.: Spectral reflectance ratio of rice canopy for estimating crop nitrogen status, Plant Soil, 122, 295-297, 1990.

Tan, S. C., Shi, G. Y., Shi, J. H., Gao, H. W., and Yao, X.: Correlation of Asian dust with chlorophyll and primary productivity in the coastal seas of China during the period from 1998 to 2008 , J. Geophys. Res., 116, G02029, doi:10.1029/2010JG001456, 2011.

Ustin, S. L., Gitelson, A. A., Jacquemoud, S., Schaepman, M., Asner, G. P., Gamon, J. A., and Zarco-Tejada, P.: Retrieval of foliar information about plant pigment systems from high resolution spectroscopy, Remote Sens. Environ., 113, S67-S77, 2009.

Vogelmann, J. E., Rock, B. N., and Moss, D. M.: Red edge spectral measurements from sugar maple leaves. Int. J. Remote sens., 14, 1563-1575, 1993.

Weber, U., Jung, M., Reichstein, M., Beer, C., Braakhekke, M. C., Lehsten, V., Ghent, D., Kaduk, J., Viovy, N., Ciais, P., Gobron, N., and Rödenbeck C.: The interannual variability of Africa's ecosystem productivity: a multi-model analysis, Biogeosciences, 6, 285-295, doi:10.5194/bg-6-285-2009, 2009.

Wellburn, A. R.: The spectral determination of chlorophylls a and $\mathrm{b}$, as well as total carotenoids, using various solvents with spectrophotometers of different resolution, J. Plant Physiol., 144, 307-313, 1994.

Whittaker, R. H. and Marks, P. L.: Methods of assessing terrestrial productivity, in Primary Productivity of the Biosphere, edited by: Lieth, H., and Whittaker, R. H., Springer-Verlag, NY, 55-118, 1975 ,

Wuyts, N., Massonnet, C., Dauzat, M., and Granier, C.: Structural assessment of the impact of environmental constraints on Arabidopsis thaliana leaf growth: a 3-D approach, Plant Cell Environ., 35, 1631-1646, 2012.

Zygielbaum, A. I., Gitelson, A. A., Arkebauer, T. J., and Rundquist, D. C.: Non-destructive detection of water stress and estimation of relative water content in maize, Geophys. Res. Lett., 36, L12403, doi:10.1029/2009GL038906, 2009. 